\title{
How the love of muscle can break a heart: Impact of anabolic androgenic steroids on skeletal muscle hypertrophy, metabolic and cardiovascular health
}

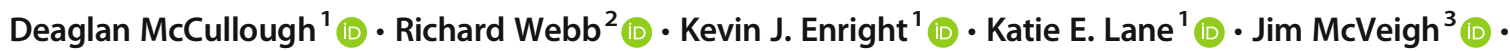 \\ Claire E. Stewart ${ }^{1}$ (D) $\cdot$ Ian G. Davies ${ }^{1}$ (D)
}

Accepted: 16 November 2020 / Published online: 2 December 2020

(C) The Author(s) 2020

\begin{abstract}
It is estimated $6.4 \%$ of males and $1.6 \%$ of females globally use anabolic-androgenic steroids (AAS), mostly for appearance and performance enhancing reasons. In combination with resistance exercise, AAS use increases muscle protein synthesis resulting in skeletal muscle hypertrophy and increased performance. Primarily through binding to the androgen receptor, AAS exert their hypertrophic effects via genomic, non-genomic and anti-catabolic mechanisms. However, chronic AAS use also has a detrimental effect on metabolism ultimately increasing the risk of cardiovascular disease (CVD). Much research has focused on AAS effects on blood lipids and lipoproteins, with abnormal concentrations of these associated with insulin resistance, hypertension and increased visceral adipose tissue (VAT). This clustering of interconnected abnormalities is often referred as metabolic syndrome (MetS). Therefore, the aim of this review is to explore the impact of AAS use on mechanisms of muscle hypertrophy and markers of MetS. AAS use markedly decreases high-density lipoprotein cholesterol (HDL-C) and increases low-density lipoprotein cholesterol (LDL-C). Chronic AAS use also appears to cause higher fasting insulin levels and impaired glucose tolerance and possibly higher levels of VAT; however, research is currently lacking on the effects of AAS use on glucose metabolism. While cessation of AAS use can restore normal lipid levels, it may lead to withdrawal symptoms such as depression and hypogonadism that can increase CVD risk. Research is currently lacking on effective treatments for withdrawal symptoms and further long-term research is warranted on the effects of AAS use on metabolic health in males and females.
\end{abstract}

Keywords Anabolic-androgenic steroids · Metabolic syndrome $\cdot$ High-density lipoprotein cholesterol $\cdot$ Low-density lipoprotein cholesterol $\cdot$ Insulin resistance $\cdot$ Cardiovascular disease

\section{Introduction}

The fine margins of winning and losing in athletic competitions has always encouraged innovative techniques to help athletes gain a competitive advantage with little regard to the potential negative consequences. Although research into sex

Deaglan McCullough

d.mccullough@2015.ljmu.ac.uk

Ian G. Davies

I.G.Davies@ljmu.ac.uk

1 Research Institute of Sport and Exercise Science, Liverpool John Moores University, Liverpool, UK

2 Faculty of Science, Liverpool Hope University, Liverpool, UK

3 Substance Use and Associated Behaviours Group, Manchester Metropolitan University, Manchester, UK hormones existed in the early 19th century, it was only in the 1930s when the anabolic effects of testosterone were demonstrated [1]. Shortly thereafter, the hormone started to be used by competitive athletes to increase muscle mass and performance, however, the British Association of Sports Medicine and the American College of Sports Medicine continued to deny its potential benefits until the 1970s [2, 3]. The use of testosterone and its derivatives were later banned by the International Olympics Committee in 1974 [4]. Due to advancements in technology and pharmacology, a range of anabolic androgenic steroids (AAS) (Table 1, [5, 6]) began to be commonly used by the recreational gym-user in the $1980 \mathrm{~s}$, primarily by young men to improve body image [1, 7]. Due to this rise in use and the associated adverse effects of AAS, many countries changed their legislation to incorporate AAS to regulate its use and distribution in the 1990s [8-10]. The world anti-doping agency was created in 1999 to protect 
athletes from the detrimental health risks of AAS use and to ensure maintenance of the integrity of sport globally $[4,11]$.

It is currently estimated that $6.4 \%$ of males and $1.6 \%$ of females use AAS globally, with recreational sportspeople being the highest users [12]. Although it is common for individuals to use AAS for multiple reasons, the greatest motivation to use AAS is primarily to improve body image, while competitive bodybuilding and athletic performance (nonbodybuilding) are secondary and tertiary respectively [12-15]. The Middle East has relatively significantly high levels of AAS use while use in South America, Europe, North America, Oceania and Africa ranges from 5-2\% of the population, highlighting the global issue at hand [12]. However, the significantly higher prevalence rates in the Middle East may be due to the majority of studies relying on self-reports from athletes rather than general populations [12]

\subsection{Effects on skeletal muscle}

Testosterone and its AAS derivatives increase muscle protein synthesis (MPS) and accretion, satellite cell activation and possibly decrease catabolic pathways via genomic and nongenomic mechanisms (Fig. 1) [16]. Genomic actions of AAS occur when androgens bind to the nuclear androgen receptor (AR) and translocate to the cell nucleus, binding to specific

Table 1 List of injectable and oral AAS and typical doses used

\begin{tabular}{ll}
\hline Injectable AAS & Typical weekly dose \\
Boldenone Undecanoate & $200-400 \mathrm{mg}$ \\
Drostanolone Propionate & $300-450 \mathrm{mg}$ \\
Methenolone Enanthate & $200-400 \mathrm{mg}$ \\
Nandrolone Decanoate & $200-400 \mathrm{mg}$ \\
Stanozolol & $150-700 \mathrm{mg}$ \\
Testosterone Cypionate & $200-600 \mathrm{mg}$ \\
Testosterone Enanthate & $200-600 \mathrm{mg}$ \\
Testosterone Propionate & $150-300 \mathrm{mg}$ \\
Testosterone Suspension & $150-700 \mathrm{mg}$ \\
Trenbolone Acetate & $150-300 \mathrm{mg}$ \\
Trenbolone Enanthate & $200-300 \mathrm{mg}$ \\
Trenbolone Hexahydrobenzylcarbonate & $150-230 \mathrm{mg}$ \\
Oral AAS & Daily dose \\
4-chlorodehydromethyltestosterone & $20-80 \mathrm{mg}$ \\
Fluoxymesterone & $20-40 \mathrm{mg}$ \\
Methandrostenolone, Methandienone & $20-40 \mathrm{mg}$ \\
Mesterolone & $50-100 \mathrm{mg}$ \\
Oxandrolone & $20-40 \mathrm{mg}$ \\
Oxymetholone & $50-100 \mathrm{mg}$ \\
Stanozolol & $20-50 \mathrm{mg}$ \\
Testosterone Undecanoate & $80-160 \mathrm{mg}$ \\
\hline
\end{tabular}

DNA sequences resulting in enhanced transcription of target anabolic genes [17, 18]. AAS also exert non-genomic actions by binding of the membrane-located AR and additional membrane receptors such as endothelial growth factor receptor (EGFR) and sex hormone-binding globulin receptor (SHBGR) that also alter anabolic/catabolic signalling pathways [17, 18]. Resistance exercise also increases muscle MPS and satellite cell activation resulting in skeletal muscle hypertrophy [19, 20]. Although testosterone administration and resistance exercise alone may increase skeletal muscle hypertrophy, the combination of both results in enhanced skeletal muscle hypertrophy [21]. As a result, AAS are commonly used in conjunction with exercise to increase muscle mass and improve perceived body image $[1,23]$.

\subsection{Effects on metabolic health}

Regular exercise is undoubtedly beneficial for mental, physical and metabolic health [22]. However, the potential benefits acquired from regular exercise may be reduced with chronic AAS use as AAS users are at a higher risk of developing cardiovascular disease (CVD), psychological disorders, neuroendocrine disorders, sex-specific disorders (aromatisation and hypogonadism in males and virilisation in females) and a range of other disorders (Table 2) [7, 23-26]. Long term AAS use has been shown to result in premature death due to cardiovascular events; however, due to AAS use only being prevalent since the $1980 \mathrm{~s}$, long term longitudinal studies, on their impact, are scarce [27]. Furthermore, the direct impact of AAS use on health is difficult to determine as users reportedly use other substances to complement their AAS use while also using a variety of AAS types, doses and cycles [13, 28]. AASrelated polysubstance use also includes other anabolic agents such as insulin-like growth factor-I (IGF-I) and growth hormone (hGH); drugs to prevent AAS-related adverse effects, other image enhancing drugs (clenbuterol, diuretics and thyroid hormones) and psychoactive drugs $[13,28]$. The chemical interactions of AAS-related polysubstance use may also elicit additional adverse health outcomes. Quantifying the adverse effects of these drugs is further complicated by the prevalence of adulterated products, an inevitable consequence of the illicit market [29].

Metabolic syndrome (MetS) is the constellation of the often interrelated metabolic abnormalities that lead to increased risk of CVD, which are the number one cause of death globally $[30,31]$. It is most commonly associated with sedentary/obese populations and is defined by having a combination of some, but not all, of high triglycerides (TG), low high-density lipoprotein cholesterol (HDL-C), elevated blood glucose, hypertension and elevated waist circumference [30, 32]. Insulin resistance (IR), visceral adipose tissue (VAT) and small dense low-density lipoprotein cholesterol (sdLDL-C) also highly correlate with MetS [30]. Although AAS users are highly 
active, they are also at risk of CVD as AAS use has been reported to increase the risk of sudden cardiac arrest as a result of cardiac remodelling and abnormal cardiac function [33-35]. The use of AAS reportedly results in polycythaemia, reduced left ventricular and diastolic function and accelerated atherosclerosis compared to non-use $[24,36]$. AAS use may affect blood pressure (BP) and metabolism which ultimately increases CVD risk in addition to altered cardiac function [33]. Furthermore, AAS use can increase low-density lipoprotein cholesterol (LDL-C) and decrease high-density lipoprotein cholesterol (HDL-C) increasing the risk of developing atherosclerosis and hence CVD [33], particularly given that AAS use could result in lower insulin sensitivity and higher levels of VAT compared to matched controls [37]. Therefore, although most AAS users have high levels of activity and low adiposity, they can also share similar metabolic characteristics of obese/sedentary populations such as the MetS, thereby increasing risk of CVD.

\subsection{AAS withdrawal}

While increasing levels of lean mass has an inverse relationship with CVD risk, AAS use has such a deleterious effect on health that it is not recommended to use for appearance or performance reasons [7,38]. Discontinuing AAS use can be a difficult process as immediate cessation may also have a detrimental effect on health and wellbeing. The withdrawal effects of AAS can cause hypogonadism, depression and fatigue, reduced libido, leading to relapse and AAS dependency [7, 39]. Current evidence on successful treatments for cessation of AAS use are scarce and further research is required, but potential strategies for males include testosterone replacement therapy (TRT), selective estrogen receptor modulators (SERM), human chorionic gonadotropin (hCG) and aromatase inhibitors [40, 41]. As a result, up to date guidance and information on the risks of commencing and ceasing AAS use along with effective treatments for withdrawal symptoms are required to prevent adverse health outcomes.

\section{Aim and scope}

Although previous reviews have focused on the effects of AAS use on blood lipid and lipoproteins profiles [33, 42], the effects on overall metabolism have yet to be reviewed. Abnormal lipid metabolism is commonly associated with impaired glucose metabolism, hypertension and VAT accumulation and this may also be the case in AAS users [30]. Therefore, the objectives of this review are to: 1, highlight the mechanisms by which AAS exert their hypertrophic effects on skeletal muscle; 2, explore the impact of AAS use on lipid, lipoprotein and glucose metabolism, all indicators of MetS and 3, explore the negative effects of AAS withdrawal and potential treatments. With the substantial levels of AAS use [7, 12], better knowledge of these interrelated mechanisms and issues may lead to targeted interventions to reduce the potential harm that may be associated with AAS use.

\section{Mechanism of action on skeletal muscle}

\subsection{Genomic-mediated mechanisms}

The primary action of AAS is to bind to the nuclear AR located in the cytoplasm which results in their translocation to the nucleus following disassociation of the AR complex with chaperone (Hsp90, Hsp70) and co-chaperone proteins (Hsp organising protein (Hop)) [43, 44]. At the nucleus the androgen/AR complex moderates gene transcription by binding to the ARE of the DNA [17, 45]. Transcription is altered further by the recruitment co-activators such as cAMP response element-binding protein (CREB)-binding protein (CBP)/p300 and steroid receptor coactivator ( $\mathrm{Src}$ ) 1, 2 and 3 $[17,45,46]$. This, in turn, upregulates expression of genes related to protein accretion and anabolism such as IGF-I, nutrient sensing, storage and transporting (Lipin, GLUT3 and SAT2) and satellite cell differentiation (myogenin), while also increasing satellite cell number [47-50]. ARE binding may also downregulate genes involved in muscle atrophy such as I-Kappa kinase alpha $(\operatorname{IKK} \alpha)[47,51]$ (Fig. 1). The transactivation domain of the AR is susceptible to a CAG repeat polymorphism within the first exon, which may regulate AR activity. The number of CAG repeats typically ranges from 11 to 31 triplets in length and is inversely associated with transactivational activity of the AR [43]. An increase in CAG repeats is associated with elevated testosterone levels, perhaps due to decreased AR activity, which may affect hypothalamic-
Table 2 Diseases associated with chronic AAS use

\begin{tabular}{llll}
\hline Cardiovascular & Psychological & Neuroendocrine & Other \\
\hline Cardiomyopathy & Depression & Neurotoxicity & Hepatoxicity \\
Coronary heart disease & Mood disorders & Reduced grey matter & Hypogonadism (males) \\
Sudden cardiac death & Substance abuse & Thinner and smaller cortices & Virilisation (females) \\
Stroke & Dependence & Cognitive impairment & Acne \\
Myocardial infarction & & & Fertility \\
Hypertension & & & Cancer \\
\hline
\end{tabular}




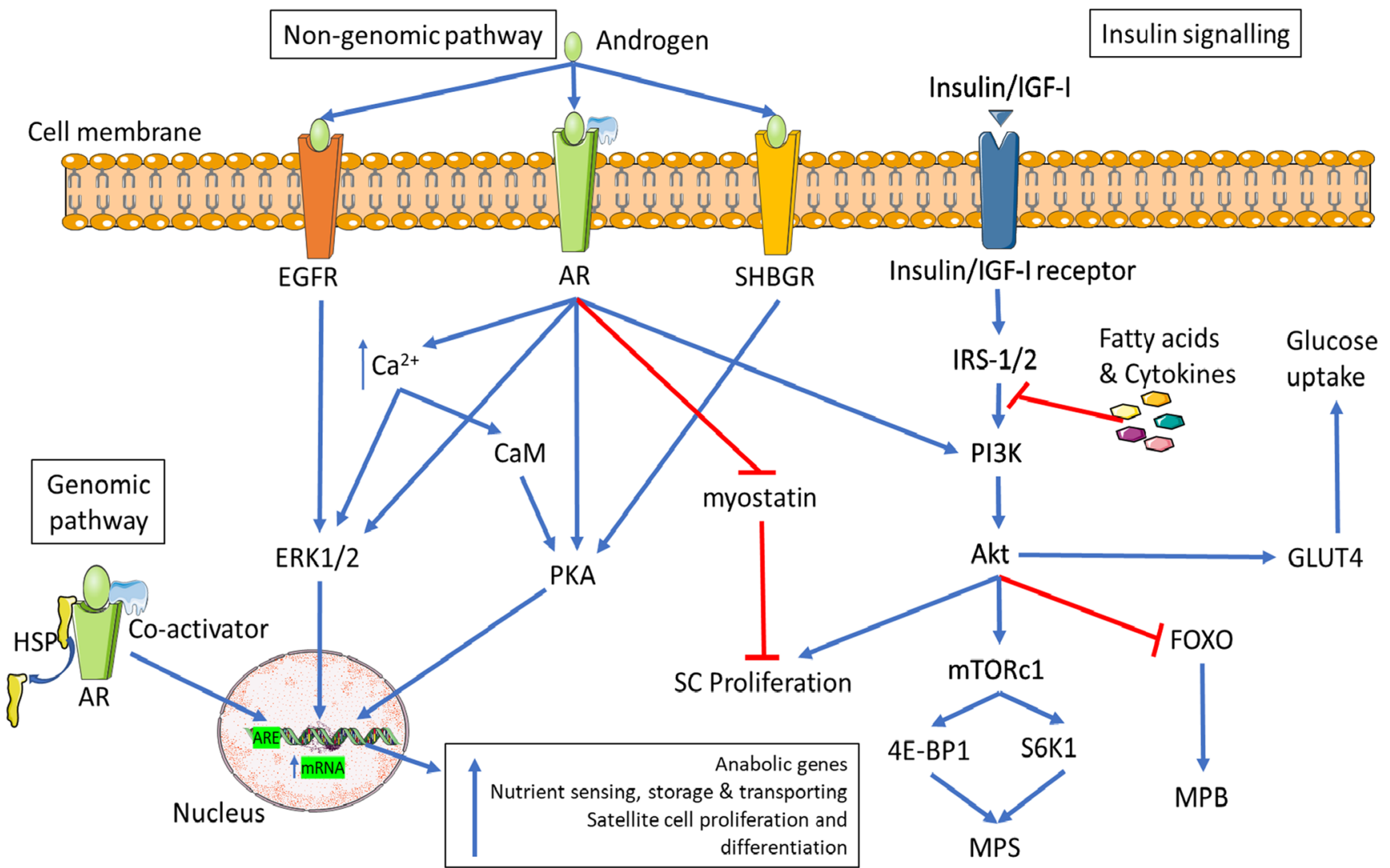

Fig. 1 Genomic and non-genomic mechanisms of AAS induced skeletal muscle hypertrophy and mechanisms of insulin signalling and resistance. Genomic pathway: Androgen binding of the AR complex causes translocation to the nucleus following dissociation of heat shock proteins (HSP). The androgen/AR complex regulates gene transcription on the androgen response element (ARE) of DNA. Non-genomic pathway: In addition to the AR, androgens can activate other membranebound receptors such as EGFR and SHBGR. This causes an increase in intracellular calcium $(\mathrm{Ca} 2+)$, activation of several second messenger signalling such as extracellular regulated kinases $1 / 2$ (ERK 1/2), protein kinase A (PKA), calmodulin ( $\mathrm{CaM})$ and phosphatidylinositol-3phosphate kinase (PI3K)/Akt/mTORc1 pathways and deactivation of myostatin pathway. Activation of these genomic and non-genomic pathways leads to skeletal muscle hypertrophy via upregulating gene

pituitary feedback regulation although no association has been observed with muscle mass in young males (25-45 years) [52]. There is currently a lack of evidence on the response of AAS in relation to the amount of AR CAG repeats.

\subsection{Non-genomic mediated adaptations}

Non-genomic actions of AAS are characterised by the speed in which they exert their effects (within minutes) thus indicating activities independent of transcription [17, 53]. AAS have been reported to exert non-genomic effects via membrane-located receptors; membrane-located AR, EGFR, and SHBGR [17]. Binding of these receptors leads to an increase in intracellular calcium and activation of transcription of anabolic genes, nutrient sensing, storage and transporting. While also upregulating satellite cell proliferation, differentiation, MPS and inhibiting muscle protein breakdown (MPB). Insulin/IGF-1 signalling pathway: Insulin/IGF-1 bind to the insulin/IGF-1 receptor on the cell membrane inflicting tyrosine phosphorylation. The now activated receptor causes phosphorylation of insulin receptor substrate-1/2 (IRS-1/2) activating the PI3K/Akt signalling cascade leading to satellite cell proliferation; MPS via mTORc1, 4E-binding protein 1 (4E BP1) and p70 S6 kinase 1 (S6K1) activation; glucose uptake via GLUT4 translocation and inhibition of forkhead $\mathrm{O}$ transcription factor (FOXO) leading to reduced MPB. Abnormal levels of circulating fatty acids and inflammatory cytokines result in serine/threonine phosphorylation of IRS-1 causing insulin resistance.

several second messenger signalling cascades including; mitogen-activated protein kinases (MAPK), ERK 1/2, PKA, PI3K/Akt and CaM pathways [17, 54, 55]. Activation of PI3K/Akt by testosterone, triggers mTORc1, a key regulator of protein turnover via activation of the eukaryotic initiation factor 4E-BPs and S6K1 [19, 56]. Resistance exercise also activates S6K1 via mTORc1, increasing MPS and muscle hypertrophy [57, 58]. The combination of testosterone and resistance exercise further increases mTORc1, 4E-BP1 and S6K1 activation compared to either alone [59]. These signalling cascades upregulate transcription, satellite cell proliferation, muscle protein synthesis and reduce apoptosis ultimately resulting in skeletal muscle hypertrophy $[17,54,55,60]$ (Fig. 1). 


\subsection{Anti-catabolic effects of AAS}

In addition to the genomic and non-genomic effects of AAS decreasing atrophy related gene expression and activity of catabolic pathways (FOXO pathway), AAS may cause direct inhibition on glucocorticoid receptor (GR) signalling and/or its expression [5]. Binding of the GR by agonists increases skeletal muscle atrophy and thereby inhibition of this pathway will increase net protein balance and further increase muscle hypertrophy [61]. Compared to young muscle, aged muscle shows a decrease in function and size, of which the mechanisms are multifactorial [62]. Increases in apoptosis may be implicated in this decline of ageing muscle as old mice were observed to have increased rates of apoptosis of skeletal muscle compared to young [63]. Treatment of old mice with testosterone reduced apoptotic rate to similar levels of young mice while also regenerating myofiber size [63]. Myostatin, an endogenous inhibitor of muscle growth through negative regulation of satellite cell proliferation and differentiation, was also shown to be downregulated following testosterone treatment in old mice, further highlighting its potential anticatabolic effect [63, 64] (Fig. 1). However, the specific anticatabolic effects of AAS use may only be beneficial in populations with abnormally low levels of testosterone such as ageing, as it remains to be confirmed in healthy adults with normal testosterone level.

\subsection{Resulting effect on muscle mass and/or performance}

The enhanced anabolic and reduced catabolic signalling highlights the benefits of AAS use for enhanced muscle growth yet, it wasn't until the mid-90 s that it was confirmed to result in improved athletic performance [21]. In 1996, Bhasin et al.. performed the first controlled experiment on the effects of testosterone enanthate (TestE) on muscle mass and strength in males ( $\mathrm{N}=40,19-40$ years) [21]. Energy and protein intake were match controlled and participants were randomly assigned to one of four groups (no exercise with or without TestE and exercise with or without TestE). Similar supervised training programmes were followed, and TestE groups injected $600 \mathrm{mg}$ per week of TestE intramuscularly for 10 weeks. Muscle thickness and strength showed significant $(P<0.05)$ improvements in the TestE alone and exercise alone; however, the combination of TestE and exercise had a significant $(P<0.001)$ additive effect [21]. The enhanced effect of combining AAS and resistance exercise on muscle hypertrophy and strength is most likely due to upregulation of AR activation and enhanced mTORc1 signalling as discussed above [56]. It was later reported that there is a dose-response relationship (25-600 mg p/wk) of AAS with body composition and muscle performance (Fig. 2) [65]. Furthermore, supraphysiological doses of AAS (200-
$300 \mathrm{mg}$ p/wk) significantly increased cycle performance compared to placebo-controlled participants following a 6-week resistance exercise programme [66]. Self-reported AAS use suggests that the enhanced effects on muscle mass and strength continue to be elevated with long term use (> 5 years) compared to non-users [67].

In physically active females (mean age 24 years old), 10 weeks of testosterone cream treatment $(70 \mathrm{mg} / \mathrm{wk})$ resulted in a significant $(P<0.001)$ moderate increase in testosterone levels $(0.9$ to $4.3 \mathrm{nmol} / \mathrm{L})$. This increase in testosterone levels resulted in significantly $(P<0.05)$ improved lean mass compared to a placebo-controlled group but no improvement in muscle strength was detected [68]. Although 10 weeks may not be long enough to increase muscle strength, higher doses of AAS (up to $600 \mathrm{mg}$ per week) may show greater improvements due to the dose-response relationship of AAS and muscular improvements, however, data are limited in females [65]. Furthermore, female athletes with higher endogenous testosterone levels have an increase in athletic performance in $400 \mathrm{~m}, 400 \mathrm{~m}$ hurdles, $800 \mathrm{~m}$, hammer throw and pole vault by $2-5 \%$ [69]. A recent systematic review and meta-analysis on the effects of AAS on healthy exercising adults of all ages showed that AAS use with exercise improved strength by $52 \%$ along with improved body composition vs. non-users [70]. Although data reported were highly variable, ranging in quality and lacking female representation, the evidence of translating the enhanced anabolic signalling into increased muscle mass and performance is substantial. Due to this, AAS have been viewed as a possible strategy in reducing the age-related decline in muscle mass and function (termed sarcopenia) in testosterone deficient older individuals [71]. Although resistance exercise has shown to reduce the severity of sarcopenia [72, 73], serum testosterone levels decline with age in males which may lead to testosterone deficiency and attribute to sarcopenia and frailty; therefore, low dose testosterone supplementation may attenuate this decline and even improve muscle mass and function [74]. Long term ( $>3$ years) TRT ( $\sim 75 \mathrm{mg}$ daily to achieve normal total testosterone levels) in older ( $>60$ years) men resulted in improvements in muscle strength, power and lean body mass compared to

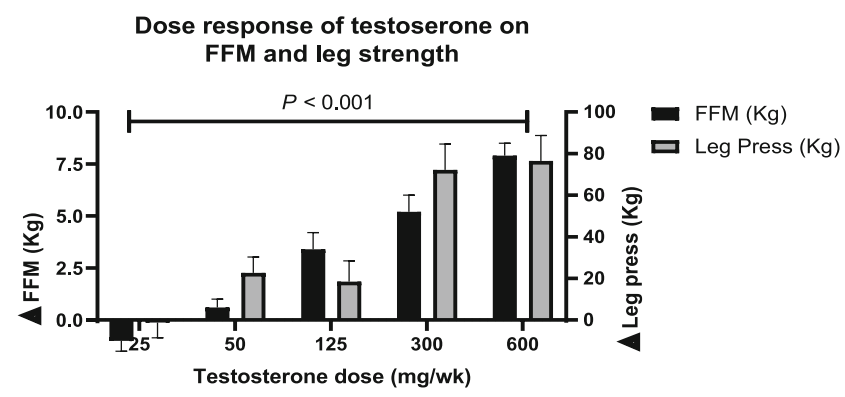

Fig. 2 The dose-response effect of testosterone on change in fat-free mass (FFM) and leg press strength after 20 weeks in combination with a resistance exercise protocol (redrawn from Bhasin et al.) [65] 
a placebo-controlled group [75]. Additionally, the testosterone trials involved 7 coordinated placebo-controlled trials with the aim of increasing deficient testosterone levels to normal levels in 788 males aged $\geq 65$ years old with transdermal TRT for one year [76]. TRT resulted in improving 6-minute walking distance in addition to increasing sexual function, mood and bone mineral density [77].

Nonetheless, TRT is only recommended for individuals who exhibit symptoms of testosterone deficiency (reduced libido, gynecomastia, depression, low bone mineral density, decreased energy, low muscle mass/strength and poor cardiovascular health profile) and low testosterone serum levels (< $12 \mathrm{nmol} / \mathrm{l})$ [78, 79]. The risks associated with TRT include infertility (in young), cardiovascular disease and prostate cancer and therefore, should be assessed on a case by case base by a clinician $[79,80]$. It has also been reported that an important motivation to take AAS was to "slow the ageing process" in older males, which may exhibit greater health risks compared to clinically prescribed TRT [81].

In summary, chronic AAS use increases skeletal muscle anabolism, which results in skeletal muscle hypertrophy, improved function and body composition via genomic, nongenomic and anti-catabolic signalling pathways. Nevertheless, the use of AAS has negative consequences on overall metabolic health through altered lipid metabolism and therefore an increase in CVD risk. With CVD being the number one cause of deaths globally, the potential clinical benefits of AAS use on skeletal muscle are far outweighed by the negative outcomes on cardiovascular health [31].

\section{Impact on metabolic health}

\subsection{Lipid metabolism}

Dyslipidaemia is associated with an increased CVD risk and is underpinned by high levels of triglycerides $>150 \mathrm{mg} / \mathrm{dL}$, LDL-C $>116 \mathrm{mg} / \mathrm{dL}$ and/or low levels of HDL-C $<40 \mathrm{mg} /$ $\mathrm{dL}$ in males and $<50 \mathrm{mg} / \mathrm{dL}$ in females [82, 83]. Although only triglycerides and HDL-C are considered components of MetS, sdLDL-C is considered an additional element to this disease [30]. LDL can be separated into 4 groups: large and buoyant (lbLDL), intermediate size and density (idLDL), small and dense (sdLDL) and very small and dense (vsdLDL) [84]. High circulating particles of sdLDL and vsdLDL indicate a greater risk of CVD events compared to total LDL alone $[84,85]$. Cholesterol is primarily synthesized in the liver and circulates around the body as very-low-density lipoprotein (VLDL) (rich in TG) of which apolipoprotein B100 (ApoB) is the major apolipoprotein (Fig. 3) [86]. Upon interaction with lipases at various tissues, the VLDL containing TG are hydrolysed, and free fatty acids are released for energy or subsequent storage as adipose tissue [87]. The remaining lipoprotein is now cholesterol-rich, TG poor LDL (or LDL-C). This LDL will bind to the hepatic LDL receptor to increase LDL-C clearance [87]. With dysregulated metabolism, as observed in MetS, there is an increase in circulating sdLDL which, has a lower affinity for the LDL receptor, therefore, having a reduced clearance rate, subsequently increasing circulating levels and CVD risk [88]. The sdLDL can also penetrate the arterial wall easier compared to $\mathrm{lbLDL}$ due to its small size increasing the risk of trapping ApoB depositing atherogenic cholesterol and increasing the risk of a CVD event [89]. High-density lipoprotein (HDL), particularly subfraction $\mathrm{HDL}_{2}$ transports cholesterol away from peripheral tissue, including arterial lesions, to the liver to be excreted, through a process of reverse cholesterol transport, thereby reducing CVD risk [90, 91]. HDL of which apolipoprotein A1 (ApoA1) is the major apolipoprotein, also has an antiinflammatory and antioxidant effect on the vascular system further reducing the potential of CVD [92]. Use of AAS has shown a reduction in HDL-C of $\geq 70 \%$ and increased LDL-C levels of $>20 \%$ [33]. Testosterone has been reported to significantly decrease HDL-C, although with differential dose and time responses. Increasing doses of Test $\mathrm{E}$ for 20 weeks in resistance-trained males has been reported to have an inverse dose-response relationship with HDL-C and Apo A1 but only $600 \mathrm{mg} / \mathrm{wk}$ was significantly $(P<0.001)$ different to baseline levels [93]. However, in contrast, $150 \mathrm{mg} / \mathrm{wk}$ for 2 weeks and a $300 \mathrm{mg}$ dose of testosterone cypionate on week 3 resulted in the largest decrease in HDL-C but no further decrease was observed with $600 \mathrm{mg} / \mathrm{wk}$ for a further 4 weeks [94]. Furthermore, 3 weeks of $600 \mathrm{mg} / \mathrm{wk}$ Test $\mathrm{E}$ administration in inactive ageing males resulted in significant decreases in HDL-C, particularly $\mathrm{HDL}_{2}$ [95]. Although $200 \mathrm{mg} / \mathrm{wk}$ of Test $\mathrm{E}$ in resistance training males showed significant decreases in HDL-C after 6 weeks, no effect was observed on $\mathrm{HDL}_{2}$ [96]. In healthy males, $200 \mathrm{mg} / \mathrm{wk}$ of Test $\mathrm{E}$ administration for 12 months had dramatic significant (mean: $1.15 \mathrm{mmol} / \mathrm{L}$ to $0.09 \mathrm{mmol} / \mathrm{L}, P<0.05$ ) decrease in fasting HDL-C levels. Interestingly, neither study observed significant deleterious changes in LDL-C or TG levels in fact, Thompson et al. $(1989)$ reported a significant $(P<0.05)$ decrease in LDL-C.

Nandrolone administration has reported contrasting effects on lipid metabolism. HDL-C has been reported to significantly decrease after a $200 \mathrm{mg}$ starting dose of nandrolone and a further $100 \mathrm{mg} / \mathrm{wk}$ for a total of 8 weeks in male bodybuilders [97]. Although in a similar design and population, $200 \mathrm{mg} / \mathrm{wk}$ of nandrolone for 8 weeks resulted in no significant change in HDL-C [98]. In healthy adults, $100 \mathrm{mg} /$ wk for 6 weeks resulted in no change in HDL-C [99]. No effect was observed on LDL-C, TGs, Apo A1 or Apo B levels in the above studies [97-99]. Nandrolone administration (200 $\mathrm{mg} / \mathrm{wk})$ for 6 months in ageing males undergoing haemodialysis resulted in significantly reduced HDL-C and increased apo B levels 


\section{NORMAL LIPOPROTEIN METABOLISM}

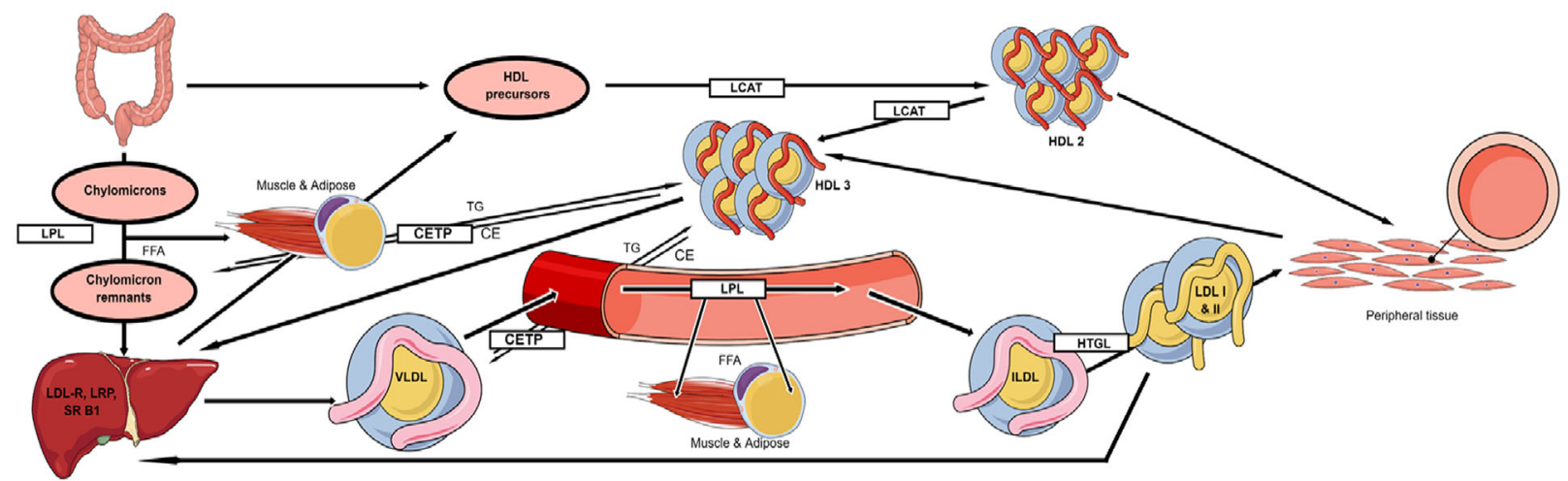

AAS LIPOPROTEIN METABOLISM

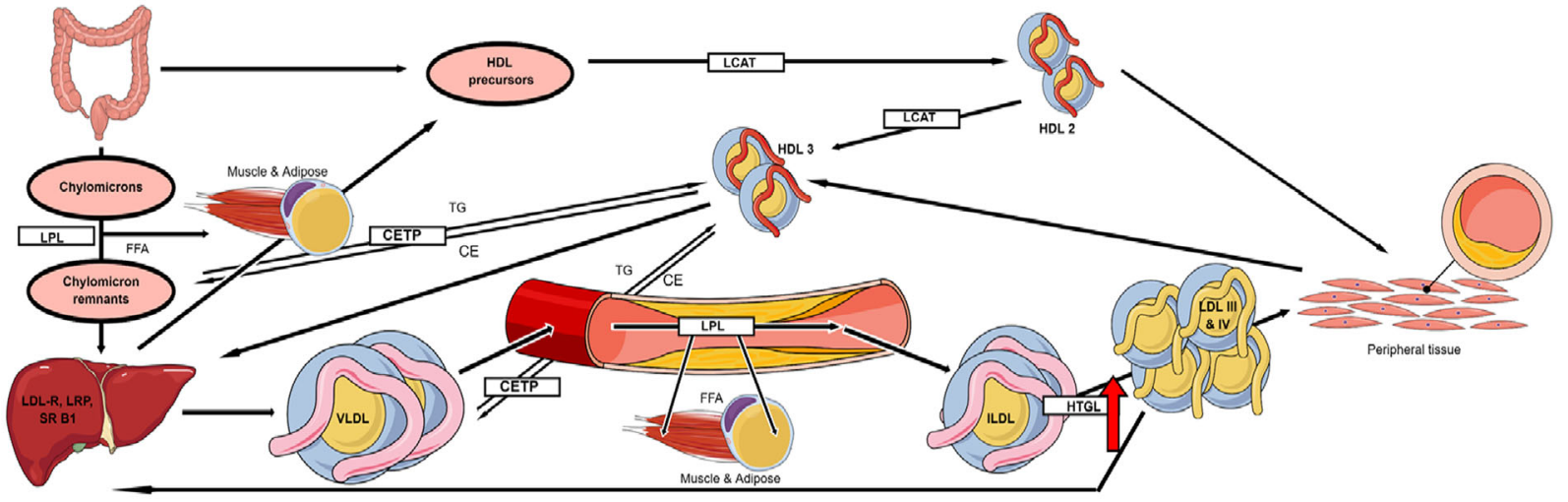

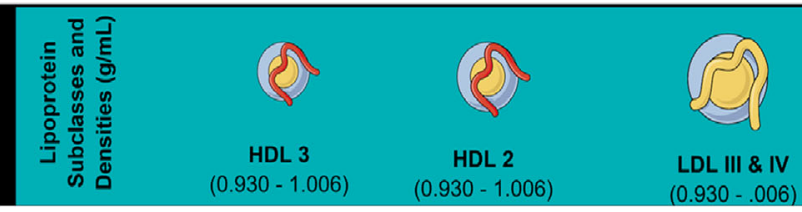

Fig. 3 Normal and AAS-influenced lipoprotein metabolism. During normal lipoprotein metabolism, intestinally produced chylomicrons carrying dietary lipids are hydrolysed by lipoprotein lipase (LPL). FFA are liberated and taken up by the liver, muscle and adipose tissue. Resulting chylomicron remnants are taken up by the liver via low-density lipoprotein receptor (LDL-R) and the LDL receptor-related protein (LRP). Meanwhile, hepatically produced VLDL transport cholesterol esters (CE) and TG through blood vessels, during which they undergo hydrolysis, releasing FFA which are taken up by peripheral tissues. This loss of TG means VLDL particles decrease in size (and therefore density) and become cholesterol-enriched and known as idLDL. Due to the action of HGTL, IDL particles become even smaller and known as LDL. LDL particles have an increased propensity to deposit cholesterol in peripheral

but had no effect on TG or Apo A1. [100]. In post-menopausal women, $50 \mathrm{mg} / \mathrm{wk}$ of nandrolone for 3 weeks significantly decreased HDL-C and Apo A1 levels [101]. In male bodybuilders, $42 \mathrm{mg} / \mathrm{wk}$ of oral stanozolol administration has shown to significantly reduce HDL-C, ApoA1 and TGs after 6 weeks while also increasing LDL-C [96]. In healthy males, one intramuscular injection of $50 \mathrm{mg}$ of stanozolol resulted in a significant reduction and increase in HDL-C and LDL-C levels respectively 28 days later [102]. Both returned to baseline levels after 56 days [102]. Similar results have been tissues; however, they primarily transport cholesterol to the liver, where they are taken up by the LDL-R. The intestine also produces precursors which contribute towards the production of HDL. Small HDL3 particles acquire CE and TG and form larger HDL2 particles which, with the assistance of lecithin-cholesterol acyltransferase (LCAT), subsequently exchange CE for even more TG with VLDL particles and chylomicrons, before travelling to the liver where they are taken up by scavenger receptor B1 (SR-B1) or LDL-R. During AAS-influenced lipoprotein metabolism HGTL is upregulated, resulting in a preponderance of more atherogenic small, dense LDL III and IV particles, as opposed the larger and more buoyant LDL I and II particles found in normal lipoprotein metabolism. There is also a severe decrease in the number of HDL 2 and 3 particles overall, which are generally regarded as being atheroprotective.

observed in postmenopausal females with osteoporosis, as $42 \mathrm{mg} / \mathrm{wk}$ of oral stanozolol resulted in significant reductions in HDL-C and ApoA1 levels after 2 weeks and was maintained until the end of the treatment at 6 weeks along with an increase in LDL-C levels [103]. No change was observed in TG levels [103].

Differences in study designs, populations and lack of dietary control in some studies has resulted in differing responses in lipid metabolism with AAS administration. Nonetheless, increasing doses of testosterone administration has a large 
negative impact on HDL-C with no adverse effect on other lipid markers. Although inconsistent, the negative effects of nandrolone administration are primarily observed on HDL-C levels, however, nandrolone does appear to consistently reduce lipoprotein(a) (Lp (a)) levels [98, 100, 101], an independent risk factor of CVD [104, 105], yet further research is warranted on the potential benefits of nandrolone, if any. In contrast, stanozolol administration may have a greater deleterious effect on lipid metabolism as it has shown to negatively affect LDL-C and HDL-C levels.

Individuals who use AAS for appearance and performance reasons typically do not use one type of AAS but rather administer a polypharmacy regime which may lead to different implications on lipid metabolism.

Early studies reported that after 8 weeks of AAS administration, HDL-C and LDL-C significantly $(P<0.01)$ decreased by $49 \%$ and increased by $31 \%$ respectively [106]. Similarly, this suppression on HDL-C, particularly $\mathrm{HDL}_{2}$, is maintained after 14 weeks of selfadministration [98]. However, Bonetti et al.. only reported a significant $(P<0.05)$ decrease in HDL-C after 18 months [107]. The method of using selfadministrating participants results in a variety of AAS dosages, types and cycles being used which may lead to different health outcomes thereby making comparisons between studies difficult. Critically, however, although they may be less controlled, they may be more representative of the population compared to randomised controlled trials as it replicates the AAS and AASrelated polysubstance methods used by this unique population. A more recent cross-sectional study reported similar results in which current users of AAS, displayed $45 \%$ lower HDL-C, and $26 \%$ and $35 \%$ higher LDL-C and TG levels vs. non-AAS using controls (all $P<0.01$ ) [37]. A case study of prolonged AAS use in a 35-yearold male demonstrated an almost $100 \%$ decrease in HDL-C and a $100 \%$ increase in LDL-C during 5 years of AAS cycling [108]. Similarly, in females, HDL-C is shown to be significantly depressed with chronic AAS use compared to healthy controls. While AAS use may also exhibit an increase in plasma TG, data remains equivocal as this was only reported by Moffatt et al. [109-111]. In addition to small sample sizes in female studies, the variety in AAS use, type, dose and frequency might explain the differences in results. Although, the lipoprotein profile is undoubtedly impacted by chronic AAS use and therefore highlights the increased risk of future CVD incidence, due to the uncontrolled self-administration of AAS and other anabolic substances the severity in which it impacts health can be variable. Conversely, AAS polypharmacy is also reported to improve Lp (a) levels, similar to the effect of nandrolone administration alone [98]. Selfadministration of a variety of AAS resulted in a significant $(P<0.05)$ decrease in $\mathrm{Lp}$ (a) after 8 weeks and was maintained after 14 weeks [98]. However, 24 months of AAS use did not result in a significant decrease (mean $\pm \mathrm{SD} ; 179 \pm 117$ vs. $137 \pm 80 \mathrm{mg} / \mathrm{dL}$, $P>0.05$ ) in Lp (a) [107]. Although non-significant, it may be clinically significant as $\mathrm{Lp}(\mathrm{a})$ levels $>180 \mathrm{mg} /$ $\mathrm{dL}$ are considered high risk of CVD [82]. The implications of AAS induced improvements in $\mathrm{Lp}$ (a) concerning CVD risk are unclear and warrant further investigation. Use of AAS also doesn't appear to negatively impact TG levels in males as only one crosssectional study reported significantly $(P<0.01)$ higher TGs (although not clinically significant $<1.7 \mathrm{mmol} / \mathrm{L}$ ) with AAS use, yet self-administration studies showed no significant negative effect $[98,106,107]$. The mechanisms by which AAS negatively impact lipid metabolism are not fully understood, but the upregulated activity of hepatic triglyceride lipase (HTGL) has been implicated (Fig. 3) [95, 96]. Phospholipase activity of HTGL catabolises HDL-C and its removal from the plasma and conversion of idLDL to sdLDL [42, 112]. Research of the impact of AAS use on LDL density are limited with most focusing on total LDL-C however, one randomised controlled trial investigated the shortterm ( 3 weeks) effects of TestE administration on cholesterol associated with LDL density by density gradient ultracentrifugation (DGUC) [95]. In older eugonadal males (mean 71 years old), $600 \mathrm{mg}$ of TestE increased sdLDL-C indicating an increase in CVD risk [85, 95]. Unpublished data, by the authors, showed no significant $(P>0.05)$ difference in a cross-section of AAS using males and healthy controls in sdLDL-C. Further research is warranted on the effect of AAS use on LDL density and its associated CVD risk. The type of AAS and route of administration also has an impact on the effect of HTGL activity and lipoprotein levels. Orally administered stanozolol showed a significant $(P<0.05)$ increase in HTGL activity, leading to a significant $(P<0.05)$ increase and decrease in LDL-C and $\mathrm{HDL}_{2}-$ $\mathrm{C}$ respectively whereas injected TestE showed no significant $(P>0.05)$ change in $\mathrm{HDL}_{2}-\mathrm{C}$ after 6 weeks, but a significant $(P<0.05)$ decrease in LDL-C [96]. The slower liver clearance rate of orally administered AAS compared to injected AAS could have a greater detrimental effect on metabolic health and also increase the risk of hepatoxicity [113-115]. Interestingly, the effect of AAS on the lipoprotein profile is reversible, as former users of AAS with long term discontinuation of at least one year, are reported to have healthy lipoprotein levels $[37,116]$. The reversible effects may be seen as 
early as 10 weeks of AAS cessation as shown by a case study in a 35-year-old male [108].

\subsection{Glucose metabolism and VAT}

Key features associated with MetS are IR and VAT [30]. IR is the precursor of the development of Type 2 diabetes (T2D), with lipid accumulation and inflammation being implicated as the primary triggers [117-119]. IR can be measured by the hyperinsulinemic-euglycemic clamp with IR being defined as a glucose disposal rate below $5.6 \mathrm{mg} / \mathrm{kgFFM}+17.7 / \mathrm{min}$ [120]. Skeletal muscle is the largest tissue for insulin-induced glucose uptake [121]. Insulin binds to the insulin receptor on the cell membrane causing its tyrosine phosphorylation of the receptor (Fig. 1). The now activated insulin receptor causes phosphorylation of insulin receptor substrate-1 (IRS-1) on tyrosine residues, which allows the recruitment of the Type IA phosphatidylinositol 3' kinase (PI3K). PI3K catalyses the formation of $\mathrm{PI}(4,5)$-bisphosphate to $\mathrm{PI}(3,4,5)$-trisphosphate thus recruiting 3' phosphoinositide-dependent kinase-1 (PDK-1). PDK-1 phosphorylates protein kinase B (PKB) (also known as Akt) and the atypical protein kinase C (PKC) $[118,119,122,123]$. Akt phosphorylates 160$\mathrm{kDa}$ substrate of Akt (AS160) which stimulates translocation of GLUT4 storage vesicles to fuse at the cell surface to release GLUT4 into the plasma membrane allowing cellular glucose uptake [124, 125]. However, within IR tissue this signalling cascade is diminished possibly due to increased circulating fatty acids, inflammatory cytokines and/or reactive oxygen species (ROS) which result in serine/threonine phosphorylation of IRS- 1 . This reduces Akt activity and glucose uptake and negatively affects other downstream signalling such as protein synthesis and apoptosis (Fig. 1) [119, 122, 126]. Acute testosterone administration has shown to activate the PI3K/Akt pathway and GLUT4 translocation in vitro indicating an increase in cellular glucose uptake [54]. However, supraphysiological levels of testosterone and nandrolone have been reported to significantly $(P<0.05)$ diminish the response of insulininduced glucose uptake in rodents $[127,128]$. Rodents also showed impairments in gluconeogenesis, most likely due to the high fasting insulin levels [128]. In contrast, increasing doses of testosterone $(25-600 \mathrm{mg} / \mathrm{wk})$ for 20 weeks had no significant effect on insulin sensitivity in resistance-trained males [93]. Additionally, in a doubleblind crossover design, $300 \mathrm{mg} / \mathrm{wk}$ of Test $\mathrm{E}$ and nandrolone administration for 6 weeks did not affect glucose tolerance or fasting insulin levels in healthy males [129]. Although research is lacking, females who use AAS for performance are reported to display reduced insulin sensitivity [130]. In healthy females, up to 12 days of methyltestosterone dosing ( $5 \mathrm{mg}$ ), showed a significant
$(P<0.05)$ reduction in whole-body insulin sensitivity [130]. Similarly, in postmenopausal females, $120 \mathrm{mg}$ of testosterone undecanoate per week resulted in a significant decrease in insulin sensitivity [131]. Hyperandrogenism in females is a significant risk factor in developing polycystic ovary syndrome (PCOS) and PCOS increases the risk of developing MetS although the risk of developing CVD is currently unclear [132-135]. Interestingly, muscle strength determined by bench press and handgrip test was shown to be significantly $(P<0.05)$ higher in females with PCOS compared to healthy controls, further indicating that hyperandrogenism may be implicated in PCOS and MetS [136].

Although individual AAS use may not result in reduced insulin sensitivity in males [93, 129], limited research suggests chronic AAS polysubstance use may be detrimental to glucose metabolism as shown by Cohen et al. [137]. Powerlifting steroid users (PS) were shown to have similar fasting glucose levels as non-using powerlifters (NP) and sedentary participants; however, they had significantly $(P<0.05)$ higher fasting insulin levels that were similar to those observed in obese participants [137]. An oral glucose tolerance test (OGTT) also revealed the PS to have a significant $(P<0.05) 2$-fold increase in post-glucose glycaemia compared to NP, which was a similar increase to the obese group. Post-glucose insulinaemia in the PS group was also significantly $(P<0.01)$ higher compared to all groups, with it being at least 2-fold higher compared to obese participants [137]. The authors only report participants use of AAS although insulin is commonly used for its anabolic potential and may have also been used by participants which may have impacted the results. More recently in males, an OGTT between healthy controls, steroid-using bodybuilders and former steroid-using bodybuilders (mean discontinuation of 2.5 years) revealed that current and former AAS users had significantly $(P<0.05)$ impaired glucose tolerance compared to healthy controls [37]. Reduced insulin sensitivity in former AAS users, was associated with higher \% body fat, which may be due to reduced testosterone levels compared to healthy controls [37, 138].

Chronic AAS use suppresses the hypothalamicpituitary-testicular (HPT) axis resulting in reduced endogenous testosterone production [39]. Low testosterone levels reduce insulin sensitivity and increases risk of developing MetS and CVD [139]. Interestingly, although current users of AAS had significantly $(P<0.001)$ lower $\%$ body fat compared to healthy controls and former users, they had significantly $(P<0.05)$ greater levels of VAT and reduced adiponectin and leptin levels which are all independent predictors of IR, T2D and MetS [37, 140-143].

However, a randomised controlled trial of the doseresponse of TestE for 20 weeks showed significant 
$(P<0.05)$ decreases in VAT with higher doses, indicating supraphysiological doses do not increase VAT [144]. Although cross-sectional studies cannot determine causation, it may be more representative of long term AAS and AASassociated polysubstance use in this case. Individuals typically use a range of AAS types and other complementary drugs; doses, cycles, methods of administration and for years rather than weeks or one AAS which may explain the differences in results.

Accumulation of VAT is an important indicator of glucose tolerance, MetS and CVD risk, much more so than subcutaneous adipose tissue (SAT) [143, 145, 146]. In healthy adipose tissue, when surplus energy is consumed, the energy is stored in SAT. However, in unhealthy or IR adipose tissue, the excess energy will be deposited in VAT and a variety of organs including muscle tissue $[147,148]$. The lipolytic rate of VAT is increased compared to SAT due to the increased effect of pro-lipolytic catecholamines and decreased effect of anti-lipolytic insulin. This increases the flux of FFA to the liver, which may further increase hepatic IR [146]. Though, with AAS use, VAT was associated with lower lipolysis rates as determined by lower levels of plasma glycerol [37]. The unusual lower lipolytic activity may be attributable to reduced activity of catecholamines due to AAS compounds such as nandrolone downregulating $\beta 3$-adrenoceptor expression [149]. In addition to being involved in lipid storage and mobilisation, adipocytes are also an endocrine tissue, releasing cytokines and adipokines. An increase in VAT leads to a pro-inflammatory state as shown by an increase in Creactive protein (CRP) and tumour necrosis factor-alpha (TNF-a) which may further increase IR [150, 151]. As skeletal muscle is the largest tissue for glucose disposal, increases in muscle mass should improve insulin sensitivity; paradoxically, these results indicate that chronic AAS may cause tissue IR. This may be due to an imbalance of regulatory adipokines and cytokines from increased VAT levels and circulating lipids leading to a decreased/delayed stimulus of the PI3K/Akt signalling cascade in response to glucose ingestion, as also observed in T2D individuals [119]. This dysregulated metabolism leads to a continuous cycle of VAT and IR that potentiate each other. Furthermore, nutrient overload is reported to increase IR via mTORc1 dependent pathway. Chronic activation of S6K1 mediated by mTORc1, inflicts serine phosphorylation of IRS1 leading to reduced insulin sensitivity $[152,153]$. For example, chronic high glucose concentrations in murine skeletal muscle cells (C2C12 myoblasts) induce IR and reduced Akt stimulation; however, inhibition of mTOR/S6K1 signalling with rapamycin restored insulin induced Akt stimulation [154]. It may be possible that chronic AAS use, leading to hyperactivation of mTORc1/S6K1 signalling may cause IR (Fig. 4). Estradiol has shown to be significantly $(P<0.01)$ higher with AAS use compared to healthy controls and may also be a cause of IR in this population. The conversion of testosterone to estradiol resulting in a decrease in the testosterone to estradiol ratio has been implicated in the development of MetS in older males [155]. Additionally, estradiol is reported to bind to insulin and the insulin receptor further highlighting its potential role in inducing IR (Fig. 4) [156].

Research is currently lacking on the prevalence of increased levels of VAT with AAS use, most likely due to AAS typically reducing fat and to its dysregulation of insulin sensitivity. This field of research warrants further investigation.

\subsection{Hypertension}

Hypertension is highly associated with MetS and CVD risk $[30,157]$. Hypertension is caused by an increase in vascular stiffness due to degenerative changes in the extracellular matrix (ECM) derived from an imbalance of arterial scaffolding proteins such as elastin and collagen [158]. Chronic low-grade inflammation, underpinned by cytokines such as CRP, TNF-a and interleukin-6, induced by ageing, T2D or an atherogenic lipid profile results in endothelial and smooth muscle cell proliferation, hypertrophy, remodelling and apoptosis $[159,160]$. This vascular proinflammatory state characterised by angiotensin II results in upregulation of matrix metalloproteinases (MMPs) leading to degradation of elastin fibres and increased collagen deposition resulting in ECM remodelling and arterial stiffening [161, 162]. Furthermore, metabolic disorders such as T2D can cause disruption of vasodilation (nitric oxide) and vasoconstriction (endothelin) regulators resulting in hypertension [160].

Hypertension, as a result of chronic AAS use, is under debate due to conflicting data [33]. Although further research is required, there is some evidence to suggest that chronic AAS use in males may lead to increased BP [33, 163-165]. By contrast, early studies suggested that AAS use did not have a detrimental effect on BP even with 24-hour monitoring [97, $106,166]$. Short-term ( $<8$ weeks) testosterone $(200 \mathrm{mg} / \mathrm{wk})$ and nandrolone (100-200 mg/wk) administration resulted in no change in systolic or diastolic BP [97, 167] however, long term-controlled studies are lacking.

Lenders et al., reported AAS polysubstance use to have a significant $(P<0.05)$ increase in systolic BP $(\mathrm{SBP})$ after an average AAS use of 5 months although the increase was not clinically relevant $(118 \pm 2.2$ to $121 \pm 2.4 \mathrm{mmHg})$ [106] Nevertheless, more recent studies have shown chronic AAS polysubstance use to have significantly $(P<0.05)$ higher SBP compared to healthy controls and former AAS users [163, 165]. These results may be clinically relevant as mean SBP was reported to be $132 \mathrm{mmHg}$ and $138 \mathrm{mmHg}$ in current AAS users $[163,165]$. Current and former AAS users were also reported to have significantly $(P<0.05)$ increased aortic 
Fig. 4 Potential mechanisms of insulin resistance with chronic anabolic steroid use. Chronic upregulation of S6K1 via activation of PI3K/Akt signalling cascade by AAS may reduce insulin sensitivity due to inhibition of IRS- 1 by S6K 1 as seen with nutrient overload models. Furthermore, chronic AAS use may lead to an increase in VAT increasing circulating fatty acids and/or inflammatory cytokines causing inhibition of IRS-1 and reducing insulin sensitivity. Aromatisation of testosterone may lead to increasing levels of Estradiol causing IR by binding to insulin and the insulin receptor.

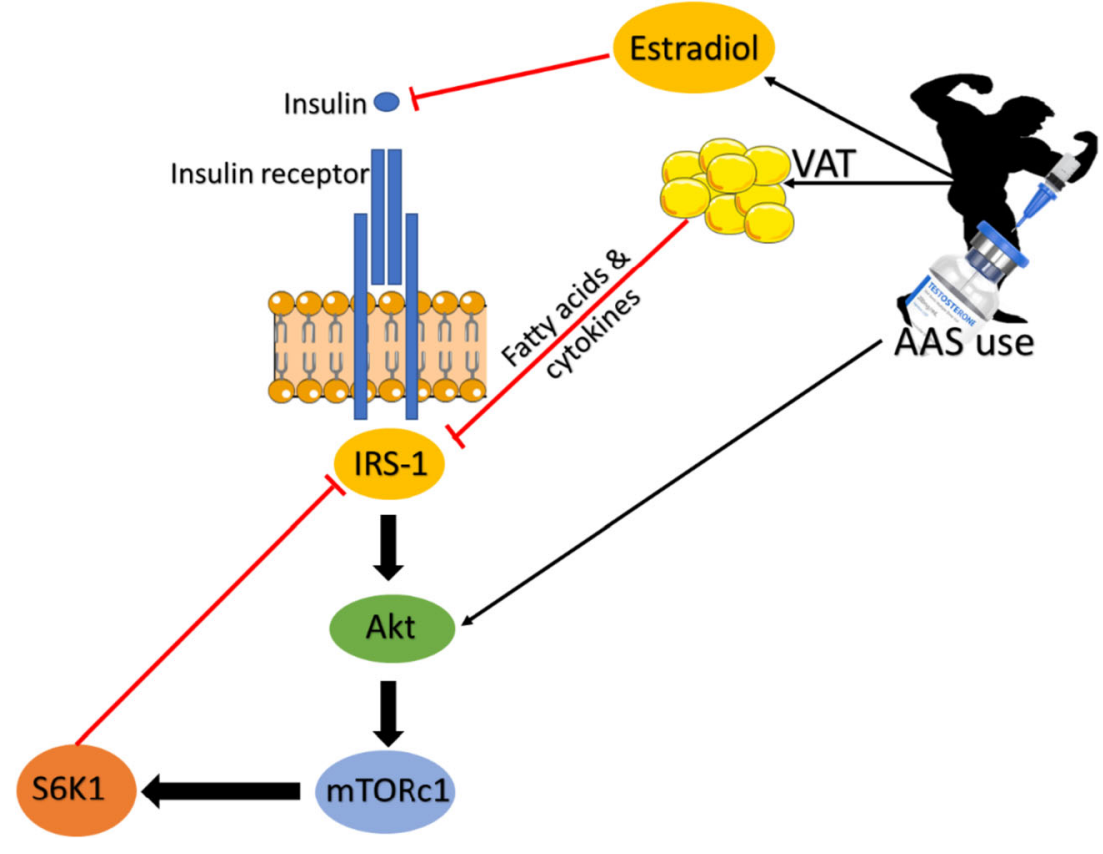

stiffness. These higher levels in aortic stiffness and SBP were associated with the significantly $(P<0.05)$ lower midregional pro-atrial natriuretic peptide (MR-proANP) in AAS users [163]. ANPs regulate vasodilation, reduce reninangiotensin-aldosterone system activity and sympathetic nerve activity; yet, high levels of MR-proANP are associated with hypertension and incidence of mortality $[168,169]$. The conflicting results regarding hypertension with AAS use may be partly due to differences in study designs. Repeated measure designs as implemented in the early studies are more indicative of causal effects compared to the most recent cross-sectional studies; however, the cross-sectional studies have larger sample sizes and potentially greater power but only association can be conferred. The lack of control on AAS type and quantity also makes it difficult to compare findings. Nonetheless, chronic AAS use may have detrimental effects on the vasculature and consequently causing hypertension and increased risk of CVD, but more long-term controlled studies are required.

\section{Reducing CVD risk}

In addition to increased LDL-C, research indicates that AAS users may develop MetS due to having low HDL-C, IR, possible hypertension and increased VAT. Considering this, they share a similar metabolic phenotype to sedentary/obese populations and have an increased risk of CVD incidence [30, 32, 33, 37, 98]. As MetS is typically associated with obese/ sedentary populations, treatments include inducing weight loss through improving lifestyle behaviours (exercise and nutrition) and bariatric surgery or pharmaceutical medication to alter negative metabolic function [170]. However, these interventions would not apply to AAS users due to their already low body fat and high physical activity [170].

To reduce MetS and CVD risk, cessation of AAS use is highly recommended as it has been shown to at least improve the lipoprotein profile, yet may have lasting effects on insulin sensitivity, BP and VAT levels [37, 106, 108, 163]. Unfortunately, total cessation can lead to withdrawal symptoms such as hypogonadism in males, infertility and depression [7, 39]. Suppression of the HPT axis results in low endogenous testosterone production leading to decreased sexual function, such as erectile dysfunction and reduced libido and may be dependent on the dose and duration of AAS use [171]. These symptoms promote relapse and AAS dependency and must be treated accordingly with pharmaceutical and cognitive behaviour therapies to help with AAS cessation and prevent relapse [172]. AAS use may also lead to gynecomastia, due to an increase in the estrogen to testosterone ratio via an increase in aromatase activity resulting in the conversion of testosterone to estradiol [173]. Therefore, use of estrogen receptor antagonists are typically used in conjunction with AAS, particularly during times of AAS cessation [41, 173]. On cessation of AAS, pharmaceuticals such as hCG, aromatase inhibitors and SERMs can reduce withdrawal symptoms although current evidence is lacking on its benefits [7, 41, 174]. Hypogonadism is also associated with MetS, therefore, total cessation of AAS use may not improve MetS symptoms and CVD risk $[175,176]$. It may be feasible to decrease AAS use instead of total cessation as low testosterone (40-80 mg per day) treatment in males with hypogonadism has been shown to improve MetS markers [177]. However, further clinical trials in AAS users, who wish to stop, are required before any true treatment can be recommended. Additionally, many users of AAS 
rely on information from websites or online forums for postcycle therapy which may lead to mismanagement of AAS withdrawal symptoms [178]. It's imperative that users of AAS seek professional advice while it is also equally important that clinicians aim to help in a non-judgemental way to reduce the likelihood of permanent adverse effects of AAS use. There is currently a lack of research on the effects of AAS withdrawal in females although they are likely to improve their lipoprotein profile but may also require treatment for depressive symptoms and amenorrhea [179-181].

\section{Conclusion}

CVD is the number one cause of deaths globally, with the obesity epidemic being a major contributor. The increasing prevalence of AAS use, particularly in young males, will exacerbate the current CVD rates. Chronic use of AAS leads to increased skeletal muscle hypertrophy and improved performance by binding to the AR. Activation of the AR by AAS leads to enhanced gene transcription, second messenger signalling, and satellite cell activation leading to increased muscle protein accretion and synthesis and possibly decreased catabolism. However, chronic AAS use not only leads to impaired cardiac function but also MetS and associated dysregulated metabolic health (IR, dyslipidaemia, VAT and BP) which is more commonly related with the sedentary/obese population. Effective management of AAS and AAS-related polypharmacy use in the first place, together with appropriate guidance on AAS cessation is key, both of which may be managed by education and psychological interventions to ultimately improve health. Therefore, further research is warranted on the long-term effects of AAS use and cessation on markers of metabolic health to provide accurate information on the potential harms in males and females. Further research is also required for treatments to aid $\mathrm{AAS}$ cessation and combat adverse metabolic health in this population.

Author contributions Deaglan McCullough, Claire E. Stewart and Ian G. Davies conceived and designed the review. The first draft of the manuscript was written by Deaglan McCullough and all authors critically revised all versions of the manuscript. All authors read and approved the final manuscript.

Funding Deaglan McCullough received funding for a $\mathrm{PhD}$ studentship by Liverpool John Moores University.

Data availability Not applicable.

\section{Compliance with ethical standards}

Conflict of interest The authors declare that they have no conflict of interest.

Consent for publication All the authors have read and approved the revised manuscript, and they are willing to publish it.
Code availability Not applicable.

Open Access This article is licensed under a Creative Commons Attribution 4.0 International License, which permits use, sharing, adaptation, distribution and reproduction in any medium or format, as long as you give appropriate credit to the original author(s) and the source, provide a link to the Creative Commons licence, and indicate if changes were made. The images or other third party material in this article are included in the article's Creative Commons licence, unless indicated otherwise in a credit line to the material. If material is not included in the article's Creative Commons licence and your intended use is not permitted by statutory regulation or exceeds the permitted use, you will need to obtain permission directly from the copyright holder. To view a copy of this licence, visit http://creativecommons.org/licenses/by/4.0/.

\section{References}

1. Kanayama G, Pope HG. History and epidemiology of anabolic androgens in athletes and non-athletes. Mol Cell Endocrinol. 2018;464:4-13. https://doi.org/10.1016/j.mce.2017.02.039.

2. Hoberman JM, Yesalis CE. The history of synthetic testosterone. Sci Am. 1995;272(2):76-81.

3. Taylor WN. Anabolic steroids and the athlete. 2nd ed. In: Taylor WN editor. Google books. 2nd ed. Jefferson: McFarland \& Company Inc.; 2001. 111-114 p.

4. Bird SR, Goebel C, Burke LM, Greaves RF. Doping in sport and exercise: anabolic, ergogenic, health and clinical issues. Ann Clin Biochem. 2016;53(2):196-221.

5. Kicman AT. Pharmacology of anabolic steroids. Br J Pharmacol. 2008;154(3):502-21.

6. De Souza GL, Hallak J. Anabolic steroids and male infertility: A comprehensive review. BJU Int. 2011;108(11):1860-5.

7. Goldman AL, Pope HG, Bhasin S. The health threat posed by the hidden epidemic of anabolic steroid use and body image disorders among young men. J Clin Endocrinol Metab. 2019;104(4):106974.

8. ACMD. Advisory Council on the Misuse of Drugs: Consideration of the anabolic steroids. London: Home Office. 2010.

9. Drug Enforcement Agency. Controlled substances - Alphabetical order [Internet]. Drug Enforcement Agency. 2019. https://www. deadiversion.usdoj.gov/schedules/orangebook/c cs alpha.pdf, https://www.dea.gov/drug-scheduling.

10. Council of Europe. Anti-Doping Convention [Internet]. 2020 [cited 2020 May 10]. https://www.coe.int/en/web/conventions/fulllist/-/conventions/treaty/135/signatures?p_auth=qSBSK9FU.

11. World Anti-Doping Agency. What is Prohibited $\mid$ World AntiDoping Agency [Internet]. 2020 [cited 2020 May 10]. https:// www.wada-ama.org/en/content/what-is-prohibited.

12. Sagoe D, Molde H, Andreassen CS, Torsheim T, Pallesen S. The global epidemiology of anabolic-androgenic steroid use: A metaanalysis and meta-regression analysis. Ann Epidemiol. 2014;24(5):383-98. https://doi.org/10.1016/j.annepidem.2014. 01.009 .

13. Begley E, McVeigh J, Hope V. Image and Performance Enhancing Drugs: 2016 National Survey Results [Internet]. 2017 [cited 2020 May 18]. http://www.ipedinfo.co.uk/resources/ downloads/2016 National IPED Info Survey report FINAL.pdf

14. Parkinson AB, Evans NA. Anabolic androgenic steroids: A survey of 500 users. Med Sci Sports Exerc. 2006;38(4):644-51.

15. Dunn M, Mazanov J, Sitharthan G. Predicting future anabolicandrogenic steroid use intentions with current substance use: Findings from an internet-based survey. Clin J Sport Med. 2009;19(3):222-7. 
16. Cheung AS, Grossmann M. Physiological basis behind ergogenic effects of anabolic androgens. Mol Cell Endocrinol. 2018;464(November 2016):14-20. https://doi.org/10.1016/j.mce. 2017.01.047.

17. Kristina Parr M, Müller-Schöll A. Pharmacology of doping agents - mechanisms promoting muscle hypertrophy. AIMS Mol Sci. 2018;5(2):145-55.

18. Wilkenfeld SR, Lin C, Frigo DE. Communication between genomic and non-genomic signaling events coordinate steroid hormone actions. Steroids. 2018;133:2-7.

19. Liu GY, Sabatini DM. mTOR at the nexus of nutrition, growth, ageing and disease. Nat Rev Mol Cell Biol. 2020;21(4):183-203. https://doi.org/10.1038/s41580-019-0199-y.

20. Egan B, Zierath JR. Exercise metabolism and the molecular regulation of skeletal muscle adaptation. Cell Metab. 2013;17(2): $162-84$.

21. Bhasin S, Storer TW, Berman N, Callegari C, Clevenger B, Phillips J, et al. The effects of supraphysiologic doses of testosterone on muscle size and strength in normal men. N Engl J Med. 1996;335(1):1-7.

22. Warburton DER, Nicol CW, Bredin SSD. Health benefits of physical activity: The evidence. Cmaj. 2006;174(6):801-9.

23. Pope HG, Wood RI, Rogol A, Nyberg F, Bowers L, Bhasin S. Adverse health consequences of performance-enhancing drugs: An endocrine society scientific statement. Endocr Rev. 2014;35(3):341-75.

24. Baggish AL, Weiner RB, Kanayama G, Hudson JI, Lu MT, Hoffmann U, et al. Cardiovascular toxicity of illicit anabolicandrogenic steroid use. Circulation. 2017;135(21):1991-2002.

25. Bjørnebekk A, Walhovd KB, Jørstad ML, Due-Tønnessen P, Hullstein IR, Fjell AM. Structural brain imaging of long-term anabolic-androgenic steroid users and nonusing weightlifters. Biol Psychiatry. 2017;82(4):294-302. https://doi.org/10.1016/j. biopsych.2016.06.017.

26. Westlye LT, Kaufmann T, Alnæs D, Hullstein IR, Bjørnebekk A. Brain connectivity aberrations in anabolic-androgenic steroid users. NeuroImage Clin. 2017;13:62-9. https://doi.org/10.1016/j. nicl.2016.11.014

27. Thiblin I, Garmo H, Garle M, Holmberg L, Byberg L, Michaëlsson K, et al. Anabolic steroids and cardiovascular risk: A national population-based cohort study. Drug Alcohol Depend. 2015;152:87-92.

28. Sagoe D, McVeigh J, Bjørnebekk A, Essilfie MS, Andreassen CS, Pallesen S. Polypharmacy among anabolic-androgenic steroid users: A descriptive metasynthesis. Subst Abus Treat Prev Policy. 2015;10(1):12.

29. Evans-Brown M, Kimergård $\mathrm{A}, \mathrm{McVeigh} J$. Elephant in the room? The methodological implications for public health research of performance-enhancing drugs derived from the illicit market. Drug Test Anal. 2009;1(7):323-6.

30. Sperling LS, Mechanick JI, Neeland IJ, Herrick CJ, Després JP, Ndumele CE, et al. The cardiometabolic health alliance working toward a new care model for the metabolic syndrome. J Am Coll Cardiol. 2015;66(9):1050-67.

31. World Health Organization. The top 10 causes of death [Internet]. 2017 [cited 2020 May 1]. http://www.who.int/en/news-room/factsheets/detail/the-top-10-causes-of-death.

32. Alberti KGMMMM, Eckel RH, Grundy SM, Zimmet PZ, Cleeman JI, Donato KA, et al. Harmonizing the metabolic syndrome: A joint interim statement of the international diabetes federation task force on epidemiology and prevention; National heart, lung, and blood institute; American heart association; World heart federation; International. Circulation. 2009;120(16):1640-5.

33. Achar S, Rostamian A, Narayan SM. Cardiac and metabolic effects of anabolic-androgenic steroid abuse on lipids, blood pressure, left ventricular dimensions, and rhythm. Am J Cardiol. 2010;106(6):893-901.

34. Maior AS, Carvalho AR, Marques-Neto SR, Menezes P, Soares PP, Nascimento JHM. Cardiac autonomic dysfunction in anabolic steroid users. Scand J Med Sci Sport. 2013;23(5):548-55.

35. Nascimento HM, Medei JE. Cardiac effects of anabolic steroids: Hypertrophy, ischemia and electrical remodelling as potential triggers of sudden death. Mini Rev Med Chem. 2011;11(5):425-9.

36. Stergiopoulos K, Brennan JJ, Mathews R, Setaro JF, Kort S. Anabolic steroids, acute myocardial infarction and polycythemia: A case report and review of the literature. Vasc Health Risk Manag. 2008;4(6):1475-80.

37. Rasmussen JJ, Schou M, Selmer C, Johansen ML, Gustafsson F, Frystyk J, et al. Insulin sensitivity in relation to fat distribution and plasma adipocytokines among abusers of anabolic androgenic steroids. Clin Endocrinol (Oxf). 2017;87(3):249-56.

38. Srikanthan P, Horwich TB, Tseng CH. Relation of muscle mass and fat mass to cardiovascular disease mortality. Am J Cardiol. 2016;117(8):1355-60.

39. Kanayama G, Hudson JI, Deluca J, Isaacs S, Baggish A, Weiner $\mathrm{R}$, et al. Prolonged hypogonadism in males following withdrawal from anabolic-androgenic steroids: An under-recognized problem. Addiction. 2015;110(5):823-31.

40. Bates G, Van Hout MC, Teck JTW, McVeigh J. Treatments for people who use anabolic androgenic steroids: A scoping review. Harm Reduct J. 2019;16(1):1-15.

41. Rahnema CD, Lipshultz LI, Crosnoe LE, Kovac JR, Kim ED. Anabolic steroid-induced hypogonadism: Diagnosis and treatment. Fertil Steril. 2014;101(5):1271-9.

42. Glazer G. Atherogenic effects of anabolic steroids on serum lipid levels: A literature review. Arch Intern Med. 1991;151(10):192533.

43. Davey RA, Grossmann M. Androgen receptor structure, function and biology: From bench to bedside. Clin Biochem Rev. 2016;37(1):3-15.

44. Echeverria PC, Picard Didier D. Molecular chaperones, essential partners of steroid hormone receptors for activity and mobility. Biochim Biophys Acta - Mol Cell Res. 2010;1803(6):641-9.

45. Bennett NC, Gardiner RA, Hooper JD, Johnson DW, Gobe GC. Molecular cell biology of androgen receptor signalling. Int J Biochem Cell Biol. 2010;42(6):813-27. https://doi.org/10.1016/ j.biocel.2009.11.013.

46. Heemers HV, Tindall DJ. Androgen receptor (AR) coregulators: A diversity of functions converging on and regulating the AR transcriptional complex. Endocr Rev. 2007;28(7):778-808.

47. Haren MT, Siddiqui AM, Armbrecht HJ, Kevorkian RT, Kim MJ, Haas MJ, et al. Testosterone modulates gene expression pathways regulating nutrient accumulation, glucose metabolism and protein turnover in mouse skeletal muscle. Int J Androl. 2011;34(1):5568.

48. Sinha-Hikim I, Roth SM, Lee MI, Bhasin S. Testosterone-induced muscle hypertrophy is associated with an increase in satellite cell number in healthy, young men. Am J Physiol - Endocrinol Metab. 2003;285(1 48 - 1):197-205.

49. Sheffield-Moore M. Androgens and the control of skeletal muscle protein synthesis. Ann Med. 2000;32(3):181-6.

50. Lee DK. Androgen receptor enhances myogenin expression and accelerates differentiation. Biochem Biophys Res Commun. 2002;294(2):408-13.

51. Rossetti ML, Steiner JL, Gordon BS. Androgen-mediated regulation of skeletal muscle protein balance. Mol Cell Endocrinol. 2017;447(3):35-44.

52. De Naeyer H, Bogaert V, De Spaey A, Roef G, Vandewalle S, Derave $\mathrm{W}$, et al. Genetic variations in the androgen receptor are associated with steroid concentrations and anthropometrics but not 
with muscle mass in healthy young men. PLoS One. 2014;9(1): e86235.

53. Deng Q, Zhang Z, Wu Y, Yu WY, Zhang J, Jiang ZM, et al. Nongenomic action of androgens is mediated by rapid phosphorylation and regulation of androgen receptor trafficking. Cell Physiol Biochem. 2017;43(1):223-36.

54. Antinozzi C, Marampon F, Corinaldesi C, Vicini E, Sgrò P, Vannelli GB, et al. Testosterone insulin-like effects: an in vitro study on the short-term metabolic effects of testosterone in human skeletal muscle cells. J Endocrinol Invest. 2017;40(10):1133-43.

55. Hamdi MM, Mutungi G. Dihydrotestosterone activates the MAPK pathway and modulates maximum isometric force through the EGF receptor in isolated intact mouse skeletal muscle fibres. J Physiol. 2010;588(3):511-25.

56. Basualto-Alarcón C, Jorquera G, Altamirano F, Jaimovich E, Estrada M. Testosterone signals through mTOR and androgen receptor to induce muscle hypertrophy. Med Sci Sports Exerc. 2013;45(9):1712-20.

57. Burd NA, Holwerda AM, Selby KC, West DWD, Staples AW, Cain NE, et al. Resistance exercise volume affects myofibrillar protein synthesis and anabolic signalling molecule phosphorylation in young men. J Physiol. 2010;588(16):3119-30.

58. Song Z, Moore DR, Hodson N, Ward C, Dent JR, O'Leary MF, et al. Resistance exercise initiates mechanistic target of rapamycin (mTOR) translocation and protein complex co-localisation in human skeletal muscle. Sci Rep. 2017;7(1):1-14.

59. Zeng F, Zhao H, Liao J. Androgen interacts with exercise through the mTOR pathway to induce skeletal muscle hypertrophy. Biol Sport. 2017;34(4):313-21.

60. Estrada M, Espinosa A, Müller M, Jaimovich E. Testosterone stimulates intracellular calcium release and mitogen-activated protein kinases via a $\mathrm{G}$ protein-coupled receptor in skeletal muscle cells. Endocrinology. 2003;144(8):3586-97.

61. Bodine SC, Baehr LM. Skeletal muscle atrophy and the E3 ubiquitin ligases MuRF1 and MAFbx/atrogin-1. Am J Physiol Endocrinol Metab. 2014;307(6):E469-84.

62. Rezuș E, Burlui A, Cardoneanu A, Rezuș C, Codreanu C, Pârvu $\mathrm{M}$, et al. Inactivity and skeletal muscle metabolism: A vicious cycle in old age. Int J Mol Sci. 2020;21(2):592.

63. Kovacheva EL, Sinha Hikim AP, Shen R, Sinha I, Sinha-Hikim I. Testosterone supplementation reverses sarcopenia in aging through regulation of myostatin, c-Jun NH2-terminal kinase, Notch, and Akt signaling pathways. Endocrinology. 2010;151(2):628-38.

64. Morissette MR, Cook SA, Buranasombati C, Rosenberg MA, Rosenzweig A. Myostatin inhibits IGF-I-induced myotube hypertrophy through Akt. Am J Physiol - Cell Physiol. 2009;297(5): 1124-32.

65. Bhasin S, Woodhouse L, Casaburi R, Singh AB, Bhasin D, Berman N, et al. Testosterone dose-response relationships in healthy young men. Am J Physiol - Endocrinol Metab. 2001;281(6 $44-6): 1172-81$.

66. Rogerson S, Weatherby RP, Deakin GB, Meir RA, Coutts RA, Zhou S, et al. The effect of short-term use of testosterone enanthate on muscular strength and power in healthy young men. J Strength Cond Res. 2007;21(2):354-61.

67. Yu JG, Bonnerud P, Eriksson A, Stal PS, Tegner Y, Malm C. Effects of long term supplementation of anabolic androgen steroids on human skeletal muscle. PLoS One. 2014;9(9):e105330.

68. Hirschberg AL, Elings Knutsson J, Helge T, Godhe M, Ekblom $\mathrm{M}$, Bermon S, et al. Effects of moderately increased testosterone concentration on physical performance in young women: A double blind, randomised, placebo controlled study. Br J Sports Med. 2019;1-7.
69. Bermon S. Androgens and athletic performance of elite female athletes. Curr Opin Endocrinol Diabetes Obes. 2017;24(3):24651 .

70. Andrews MA, Magee CD, Combest TM, Allard RJ, Douglas KM. Physical effects of anabolic-androgenic steroids in healthy exercising adults: A systematic review and meta-analysis. Curr Sports Med Rep. 2018;17(7):232-41.

71. Saad F, Röhrig G, Von Haehling S, Traish A. Testosterone deficiency and testosterone treatment in older men. Gerontology. 2017;63(2):144-56.

72. Breen L, Phillips SM. Interactions between exercise and nutrition to prevent muscle waste during ageing. Br J Clin Pharmacol. 2013;75(3):708-15.

73. Liao C, De, Tsauo JY, Wu YT, Cheng CP, Chen HC, Huang YC, et al. Effects of protein supplementation combined with resistance exercise on body composition and physical function in older adults: A systematic review and meta-analysis. Am J Clin Nutr. 2017;106(4):1078-91.

74. Spiegeleer A, De, Beckwée D, Bautmans I, Petrovic M. Pharmacological interventions to improve muscle mass, muscle strength and physical performance in older people: An umbrella review of systematic reviews and meta - analyses. Drugs Aging. 2018;35:719-34.

75. Storer TW, Basaria S, Traustadottir T, Harman SM, Pencina K, Li $Z$, et al. Effects of testosterone supplementation for 3 years on muscle performance and physical function in older men. J Clin Endocrinol Metab. 2017;102(2):583-93.

76. Snyder PJ, Ellenberg SS, Cunningham GR, Matsumoto AM, Bhasin S, Barrett-Connor E, et al. The Testosterone Trials: Seven coordinated trials of testosterone treatment in elderly men. Clin Trials. 2014;11(3):362-75.

77. Snyder PJ, Bhasin S, Cunningham GR, Matsumoto AM, Stephens-Shields AJ, Cauley JA, et al. Lessons from the testosterone trials. Endocr Rev. 2018;39(3):369-86.

78. Dimopoulou C, Ceausu I, Depypere H, Lambrinoudaki I, Mueck A, Pérez-López FR, et al. EMAS position statement: Testosterone replacement therapy in the aging male. Maturitas. 2016;84:94-9.

79. Bhasin S, Brito JP, Cunningham GR, Hayes FJ, Hodis HN, Matsumoto AM, et al. Testosterone therapy in men with hypogonadism: An endocrine society. J Clin Endocrinol Metab. 2018;103(5):1715-44.

80. Park H, Ahn S, Moon D. Evolution of guidelines for testosterone replacement therapy. J Clin Med. 2019;8(3):410.

81. Ip EJ, Trinh K, Tenerowicz MJ, Pal J, Lindfelt TA, Perry PJ. Characteristics and behaviors of older male anabolic steroid users. J Pharm Pract. 2015;28(5):450-6.

82. Mach F, Baigent C, Catapano AL, Koskinas KC, Casula M, Badimon L, et al. 2019 ESC/EAS Guidelines for the management of dyslipidaemias: Lipid modification to reduce cardiovascular risk. Eur Heart J. 2020;41(1):111-88.

83. Arnett DK, Blumenthal RS, Albert MA, Buroker AB, Goldberger ZD, Hahn EJ, et al. 2019 ACC/AHA guideline on the primary prevention of cardiovascular disease: A report of the American College of Cardiology/American Heart Association Task Force on clinical practice guidelines. J Am Coll Cardiol. 2019;74(10): e177-232.

84. Ivanova EA, Myasoedova VA, Melnichenko AA, Grechko AV, Orekhov AN. Small dense low-density lipoprotein as biomarker for atherosclerotic diseases. Oxid Med Cell Longev. 2017;2017(2):1-10.

85. Hoogeveen RC, Gaubatz JW, Sun W, Dodge RC, Crosby JR, Jiang J, et al. Small dense low-density lipoprotein-cholesterol concentrations predict risk for coronary heart disease: The Atherosclerosis Risk in Communities (ARIC) study. Arterioscler Thromb Vasc Biol. 2014;34(5):1069-77. 
86. Packard CJ, Demant T, Stewart JP, Bedford D, Caslake MJ, Schwertfeger G, et al. Apolipoprotein B metabolism and the distribution of VLDL and LDL subfractions. J Lipid Res. 2000;41(2):305-17.

87. Freeman MW, Walford GA. Lipoprotein metabolism and the treatment of lipid disorders. Endocrinol Adult Pediatr. 2015;1-2: 715-36.e7.

88. Thongtang N, Diffenderfer MR, Ooi EMM, Barrett PHR, Turner SM, Le NA, et al. Metabolism and proteomics of large and small dense LDL in combined hyperlipidemia: Effects of rosuvastatin. J Lipid Res. 2017;58(7):1315-24.

89. Sniderman AD, Thanassoulis G, Glavinovic T, Navar AM, Pencina M, Catapano A, et al. Apolipoprotein B particles and cardiovascular disease: A narrative review. JAMA Cardiol. 2019;4(12):1287-95.

90. Santos-Gallego CG, Torres F, Badimón JJ, Wu MY, Li CJ, Hou MF, et al. The beneficial effects of HDL-C on atherosclerosis: rationale and clinical results. Clin Lipidol. 2011;6(2):181-208.

91. Fuster V, Moreno PR, Fayad ZA, Corti R, Badimon JJ. Atherothrombosis and high-risk plaque: Part I: Evolving concepts. J Am Coll Cardiol. 2005;46(6):937-54.

92. Barter PJ, Nicholls S, Rye KA, Anantharamaiah GM, Navab M, Fogelman AM. Antiinflammatory properties of HDL. Circ Res. 2004;95(8):764-72.

93. Singh AB, Hsia S, Alaupovic P, Sinha-Hikim I, Woodhouse L, Buchanan TA, et al. The effects of varying doses of $\mathrm{T}$ on insulin sensitivity, plasma lipids, apolipoproteins, and C-reactive protein in healthy young men. J Clin Endocrinol Metab. 2002;87(1):13643.

94. Kouri EM, Pope HG, Oliva PS. Changes in lipoprotein-lipid levels in normal men following administration of increasing doses of testosterone cypionate. Clin J Sport Med. 1996;Vol. 6:152-7.

95. Herbst KL, Amory JK, Brunzell JD, Chansky HA, Bremner WJ. Testosterone administration to men increases hepatic lipase activity and decreases HDL and LDL size in 3 wk. Am J Physiol Endocrinol Metab. 2003;284:1112-8. ;(6 47 - 6).

96. Thompson PD, Cullinane EM, Sady SP, Chenevert C, Saritelli AL, Sady MA, et al. Contrasting effects of testosterone and stanozolol on serum lipoprotein levels. JAMA J Am Med Assoc. 1989;261(8):1165-8.

97. Kuipers H, Wijnen JAG, Hartgens F, Willems SMM. Influence of anabolic steroids on body composition, blood pressure, lipid profile and liver functions in body builders. Int J Sports Med. 1991;12(4):413-8.

98. Hartgens F, Rietjens G, Keizer HA, Kuipers H, Wolffenbuttel BHR. Effects of androgenic-anabolic steroids on apolipoproteins and lipoprotein (a). Br J Sports Med. 2004;38(3):253-9.

99. Glazer G, Suchman AL. Lack of demonstrated effect of nandrolone on serum lipids. Metabolism. 1994;43(2):204-10.

100. Teruel JL, Lasuncion MA, Rivera M, Aguilera A, Ortega H, Tato A, et al. Nandrolone decanoate reduces serum lipoprotein(A) concentrations in hemodialysis patients. Am J Kidney Dis. 1997;29(4):569-75.

101. Lippi G, Guidi G, Ruzzenente O, Braga V, Adami S. Effects of nandrolone decanoate (Decadurabolin) on serum Lp(a), lipids and lipoproteins in women with postmenopausal osteoporosis. Scand J Clin Lab Invest. 1997;57(6):507-11.

102. Small M, McArdle BM, Lowe GDO, Forbes CD, Prentice CRM. The effect of intramuscular stanozolol on fibrinolysis and blood lipids. Thromb Res. 1982;28(1):27-36.

103. Taggart HM, Applebaum-Bowden D, Haffner S, Warnick GR, Cheung MC, Albers JJ, et al. Reduction in high density lipoproteins by anabolic steroid (stanozolol) therapy for postmenopausal osteoporosis. Metabolism. 1982;31(11):1147-52.

104. Saeedi R, Frohlich J. Lipoprotein (a), an independent cardiovascular risk marker. Clin Diabetes Endocrinol. 2016;2(1):1-6.
105. Sharrett AR, Ballantyne CM, Coady SA, Heiss G, Sorlie PD, Catellier D, et al. Coronary heart disease prediction from lipoprotein cholesterol levels, triglycerides, lipoprotein(a), apolipoproteins A-I and B, and HDL density subfractions: The Atherosclerosis Risk in Communities (ARIC) Study. Circulation. 2001;104(10):1108-13.

106. Lenders JWM, Demacker PNM, Vos JA, Jansen PLM, Hoitsma AJ, van't Laar A, et al. Deleterious effects of anabolic steroids on serum lipoproteins, blood pressure, and liver function in amateur body builders. Int J Sports Med. 1988;9:19-23.

107. Bonetti A, Tirelli F, Catapano A, Dazzi D, Dei Cas A, Solito F, et al. Side effects of anabolic androgenic steroids abuse. Int $\mathbf{J}$ Sports Med. 2008;29(8):679-87.

108. Min L, Simon WR. Extremely low HDL cholesterol and increased LDL cholesterol induced by the use of anabolic steroids in a body builder: A case study. Int J Sport Exerc Med. 2018;4(4):1-4.

109. Malarkey WB, Strauss RH, Leizman DJ, Liggett M, Demers LM. Endocrine effects in female weight lifters who self-administer testosterone and anabolic steroids. Am J Obstet Gynecol. 1991;165(5):1385-90.

110. Moffatt RJ, Wallace MB, Sady SP. Effects of anabolic steroids on lipoprotein profiles of female weight lifters. Phys Sportsmed. 1990;18(9):106-15.

111. Cohen JC, Faber WM, Benade AJS, Noakes TD. Altered serum lipoprotein profiles in male and female power lifters ingesting anabolic steroids. Phys Sportsmed. 1986;14(6):131-6.

112. Santamarina-Fojo S, González-Navarro H, Freeman L, Wagner E, Nong Z. Hepatic lipase, lipoprotein metabolism, and atherogenesis. Arterioscler Thromb Vasc Biol. 2004;24(10):1750-4.

113. Niedfeldt MW. Anabolic Steroid Effect on the Liver. Curr Sports Med Rep. 2018;17(3):97-102.

114. Solbach P, Potthoff A, Raatschen HJ, Soudah B, Lehmann U, Schneider A, et al. Testosterone-receptor positive hepatocellular carcinoma in a 29-year old bodybuilder with a history of anabolic androgenic steroid abuse: A case report. BMC Gastroenterol. 2015;15(1):1-7.

115. Martin NM, Abu Dayyeh BK, Chung RT. Anabolic steroid abuse causing recurrent hepatic adenomas and hemorrhage. World $\mathrm{J}$ Gastroenterol. 2008;14(28):4573-5.

116. Urhausen A, Torsten A, Wilfried K. Reversibility of the effects on blood cells, lipids, liver function and hormones in former anabolic-androgenic steroid abusers. J Steroid Biochem Mol Biol. 2003;84(2-3):369-75.

117. Esser N, Legrand-Poels S, Piette J, Scheen AJ, Paquot N. Inflammation as a link between obesity, metabolic syndrome and type 2 diabetes. Diabetes Res Clin Pract. 2014;105(2):14150.

118. Meshkani R, Adeli K. Hepatic insulin resistance, metabolic syndrome and cardiovascular disease. Clin Biochem. 2009;42(1314):1331-46.

119. Samuel VT, Shulman GI. The pathogenesis of insulin resistance: Integrating signaling pathways and substrate flux. J Clin Invest. 2016;126(1):12-22.

120. Tam CS, Xie W, Johnson WD, Cefalu WT, Redman LM, Ravussin E. Defining insulin resistance from hyperinsulinemiceuglycemic clamps. Diabetes Care. 2012;35(7):1605-10.

121. Thiebaud D, Jacot E, DeFronzo RA, Maeder E, Jequier E, Felber JP. The effect of graded doses of insulin on total glucose uptake, glucose oxidation, and glucose storage in man. Diabetes. 1982;31(11):957-63.

122. Boucher J, Kleinridders A, Kahn CR, et al. Insulin receptor signaling in normal Cold Spring Harb Perspect Biol. 2014;6: a009191.

123. Haeusler RA, McGraw TE, Accili D. Metabolic signalling: Biochemical and cellular properties of insulin receptor signalling. Nat Rev Mol Cell Biol. 2018;19(1):31-44. 
124. Sakamoto K, Holman GD. Emerging role for AS160/TBC1D4 and TBC1D1 in the regulation of GLUT4 traffic. Am J Physiol Endocrinol Metab. 2008;295(1):E29-E37.

125. Li DT, Habtemichael EN, Julca O, Sales CI, Westergaard XO, DeVries SG, et al. GLUT4 storage vesicles: Specialized organelles for regulated trafficking. Yale J Biol Med. 2019;92(3):453-70.

126. Yang Q, Vijayakumar A, Kahn BB. Metabolites as regulators of insulin sensitivity and metabolism. Nat Rev Mol Cell Biol. 2018;19(10):654-72

127. HOLMÄNG A, BJÖRNTORP P. The effects of testosterone on insulin sensitivity in male rats. Acta Physiol Scand. 1992;146(4): 505-10.

128. Frankenfeld SP, de Oliveira LP, Ignacio DL, Coelho RG, Mattos MN, Ferreira ACF, et al. Nandrolone decanoate inhibits gluconeogenesis and decreases fasting glucose in Wistar male rats. J Endocrinol. 2014;220(2):143-53.

129. Hobbs CJ, Jones RE, Plymate SR. Nandrolone, a 19Nortestosterone, Enhances insulin-independent glucose uptake in normal men. J Clin end. 1996;81(4):3-6.

130. Diamond MP, Grainger D, Diamond MC, Sherwin RS, Defronzo RA. Effects of methyltestosterone on insulin secretion and sensitivity in women. J Clin Endocrinol Metab. 1998;83(12):4420-5.

131. Zang H, Carlström K, Arner P, Hirschberg AL. Effects of treatment with testosterone alone or in combination with estrogen on insulin sensitivity in postmenopausal women. Fertil Steril. 2006;86(1):136-44.

132. Fazleen NE, Whittaker M, Mamun A. Risk of metabolic syndrome in adolescents with polycystic ovarian syndrome: A systematic review and meta-analysis. Diabetes Metab Syndr Clin Res Rev. 2018;12(6):1083-90. https://doi.org/10.1016/j.dsx.2018.03.014.

133. Coviello AD, Legro RS, Dunaif A. Adolescent girls with polycystic ovary syndrome have an increased risk of the metabolic syndrome associated with increasing androgen levels independent of obesity and insulin resistance. J Clin Endocrinol Metab. 2006;91(2):492-7.

134. Ramezani Tehrani F, Amiri M, Behboudi-Gandevani S, BidhendiYarandi R, Carmina E. Cardiovascular events among reproductive and menopausal age women with polycystic ovary syndrome: a systematic review and meta-analysis. Gynecol Endocrinol. 2020;36(1):12-23.

135. Zhao L, Zhu Z, Lou H, Zhu G, Huang W, Zhang S, et al. Polycystic ovary syndrome (PCOS) and the risk of coronary heart disease (CHD): A meta-analysis. Oncotarget. 2016;7(23):3371521.

136. Kogure GS, Silva RC, Picchi Ramos FK, Miranda-Furtado CL, Lara LADS, Ferriani RA, et al. Women with polycystic ovary syndrome have greater muscle strength irrespective of body composition. Gynecol Endocrinol. 2015;31(3):237-42.

137. Cohen JC, Hickman R. Insulin resistance and diminished glucose tolerance in powerlifters ingesting anabolic steroids. J Clin Endocrinol Metab. 1987;64(5):960-3.

138. Mammi C, Calanchini M, Antelmi A, Cinti F, Rosano GMC, Lenzi A, et al. Androgens and adipose tissue in males: A complex and reciprocal interplay. Int J Endocrinol. 2012;2012:1-8.

139. Kelly DM, Jones TH. Testosterone. A metabolic hormone in health and disease. J Endocrinol. 2013;217(3):R25-45.

140. Frühbeck G, Catalán V, Rodríguez A, Ramírez B, Becerril S, Salvador J, et al. Involvement of the leptin-adiponectin axis in inflammation and oxidative stress in the metabolic syndrome. Sci Rep. 2017;7(1):1-8.

141. Hung J, McQuillan BM, Thompson PL, Beilby JP. Circulating adiponectin levels associate with inflammatory markers, insulin resistance and metabolic syndrome independent of obesity. Int $\mathrm{J}$ Obes. 2008;32(5):772-9.

142. D'Elia L, Strazzullo P, Iacone R, Russo O, Galletti F. Leptin levels predict the development of insulin resistance in a sample of adult
men-The Olivetti Heart Study. Nutr Metab Cardiovasc Dis. 2019;29(1):39-44. https://doi.org/10.1016/j.numecd.2018.10. 003.

143. Preis SR, Massaro JM, Robins SJ, Hoffmann U, Vasan RS, Irlbeck T, et al. Abdominal subcutaneous and visceral adipose tissue and insulin resistance in the framingham heart study. Obesity. 2010;18(11):2191-8.

144. Woodhouse LJ, Gupta N, Bhasin M, Singh AB, Ross R, Phillips J, et al. Dose-dependent effects of testosterone on regional adipose tissue distribution in healthy young men. J Clin Endocrinol Metab. 2004;89(2):718-26.

145. Lee CMY, Huxley RR, Wildman RP, Woodward M. Indices of abdominal obesity are better discriminators of cardiovascular risk factors than BMI: A meta-analysis. J Clin Epidemiol. 2008;61(7): 646-53.

146. Wajchenberg BL, Lé B, Wajchenberg O. Subcutaneous and visceral adipose tissue. Endocr Rev. 2000;21(6):697-738.

147. Després JP, Lemieux I. Abdominal obesity and metabolic syndrome. Nature. 2006;444(7121):881-7.

148. McLaughlin T, Lamendola C, Liu A, Abbasi F. Preferential fat deposition in subcutaneous versus visceral depots is associated with insulin sensitivity. J Clin Endocrinol Metab. 2011;96(11): 1756-60.

149. Alsiö J, Birgner C, Björkblom L, Isaksson P, Bergström L, Schiöth HB, et al. Impact of nandrolone decanoate on gene expression in endocrine systems related to the adverse effects of anabolic androgenic steroids. Basic Clin Pharmacol Toxicol. 2009;105(5):307-14.

150. Park HS, Park JY, Yu R. Relationship of obesity and visceral adiposity with serum concentrations of CRP, TNF- $\alpha$ and IL-6. Diabetes Res Clin Pract. 2005;69(1):29-35.

151. Kang YE, Kim JM, Joung KH, Lee JH, You BR, Choi MJ, et al. The roles of adipokines, proinflammatory cytokines, and adipose tissue macrophages in obesity-associated insulin resistance in modest obesity and early metabolic dysfunction. PLoS One. 2016;11(4):1-14.

152. Um SH, D'Alessio D, Thomas G. Nutrient overload, insulin resistance, and ribosomal protein S6 kinase 1, S6K1. Cell Metab. 2006;3(6):393-402.

153. Yoon MS, Choi CS. The role of amino acid-induced mammalian target of rapamycin complex 1 (mTORC1) signaling in insulin resistance. Exp Mol Med. 2016;48(1):e201.

154. Leontieva OV, Demidenko ZN, Blagosklonny MV. Rapamycin reverses insulin resistance (IR) in high-glucose medium without causing IR in normoglycemic medium. Cell Death Dis. 2014;5(5): 1-7. https://doi.org/10.1038/cddis.2014.178.

155. Maggio M, Lauretani F, Ceda GP, Bandinelli S, Basaria S, Paolisso G, et al. Estradiol and metabolic syndrome in older Italian men: The InCHIANTI study. J Androl. 2010;31(2):15562.

156. Root-Bernstein R, Podufaly A, Dillon PF. Estradiol binds to insulin and insulin receptor decreasing insulin binding in vitro. Front Endocrinol (Lausanne). 2014;5(JUL):1-13.

157. Sookoian S, Pirola CJ. Metabolic syndrome: From the genetics to the pathophysiology. Curr Hypertens Rep. 2011;13(2):149-57.

158. Xu J, Shi G-P. Vascular wall extracellular matrix proteins and vascular diseases. Biochim Biophys Acta - Mol Basis Dis. 2014;1842(11):2106-19.

159. Mahmud A, Feely J. Arterial stiffness is related to systemic inflammation in essential hypertension. Hypertension. 2005;46(5): 1118-22.

160. Petrie JR, Guzik TJ, Touyz RM. Diabetes, hypertension, and cardiovascular disease: Clinical insights and vascular mechanisms. Can J Cardiol. 2018;34(5):575-84. https://doi.org/10.1016/j.cjca. 2017.12.005. 
161. Sun Z. Aging, arterial stiffness, and hypertension. Hypertension. 2015;65(2):252-6.

162. Wang M, Kim SH, Monticone RE, Lakatta EG. Matrix metalloproteinases promote arterial remodeling in aging, hypertension, and atherosclerosis. Hypertension. 2015;65(4):698-703.

163. Rasmussen JJ, Schou M, Madsen PL, Selmer C, Johansen ML, Hovind $\mathrm{P}$, et al. Increased blood pressure and aortic stiffness among abusers of anabolic androgenic steroids. J Hypertens. 2018;36(2):277-85.

164. Urhausen A, Albers T, Kindermann W. Are the cardiac effects of anabolic steroid abuse in strength athletes reversible? Heart. 2004;90(5):496-501.

165. D'Andrea A, Radmilovic J, Caselli S, Carbone A, Scarafile R, Sperlongano S, et al. Left atrial myocardial dysfunction after chronic abuse of anabolic androgenic steroids: a speckle tracking echocardiography analysis. Int J Cardiovasc Imaging. 2018;34(10):1549-59. https://doi.org/10.1007/s10554-018-1370-9.

166. Palatini P, Giada F, Garavelli G, Sinisi F, Mario L, Michieletto M, et al. Cardiovascular effects of anabolic steroids in weight-trained subjects. J Clin Pharmacol. 1996;36(12):1132-40.

167. Chung T, Kelleher S, Liu PY, Conway AJ, Kritharides L, Handelsman DJ. Effects of testosterone and nandrolone on cardiac function: A randomized, placebo-controlled study. Clin Endocrinol (Oxf). 2007;66(2):235-45.

168. Khaleghi M, Saleem U, Morgenthaler NG, Turner ST, Bergmann A, Struck J, et al. Plasma midregional pro-atrial natriuretic peptide is associated with blood pressure indices and hypertension severity in adults with hypertension. Am J Hypertens. 2009;22(4):425-31.

169. Idzikowska K, Zielińska M. Midregional pro-atrial natriuretic peptide, an important member of the natriuretic peptide family: potential role in diagnosis and prognosis of cardiovascular disease. J Int Med Res. 2018;46(8):3017-29.

170. Kaur J. A comprehensive review on metabolic syndrome. Cardiol Res Pract. 2014;2014:943162.

171. Armstrong JM, Avant RA, Charchenko CM, Westerman ME, Ziegelmann MJ, Miest TS, et al. Impact of anabolic androgenic steroids on sexual function. Transl Androl Urol. 2018;7(3):483-9.
172. Tan RS, Scally MC. Anabolic steroid-induced hypogonadism Towards a unified hypothesis of anabolic steroid action. Med Hypotheses. 2009;72(6):723-8.

173. Calzada L, Torres-Calleja J, Martinez JM, Pedrón N. Measurement of androgen and estrogen receptors in breast tissue from subjects with anabolic steroid-dependent gynecomastia. Life Sci. 2001;69(13):1465-9.

174. Anawalt BD. Diagnosis and management of anabolic androgenic steroid use. J Clin Endocrinol Metab. 2019;104(7):2490-500.

175. Corona G, Rastrelli G, Morelli A, Vignozzi L, Mannucci E, Maggi M. Hypogonadism and metabolic syndrome. J Endocrinol Invest. 2011;34(7):557-67.

176. Rastrelli G, Filippi S, Sforza A, Maggi M, Corona G. Metabolic syndrome in male hypogonadism. Front Horm Res. 2018;49:13155.

177. Jones TH, Arver S, Behre HM, Buvat J, Meuleman E, Moncada I, et al. Testosterone replacement in hypogonadal men with Type 2 diabetes and/or metabolic syndrome (the TIMES2 study). Diabetes Care. 2011;34(4):828-37.

178. Karavolos S, Reynolds M, Panagiotopoulou N, McEleny K, Scally M, Quinton R. Male central hypogonadism secondary to exogenous androgens: A review of the drugs and protocols highlighted by the online community of users for prevention and/or mitigation of adverse effects. Clin Endocrinol (Oxf). 2015;82(5):624-32.

179. Nieschlag E, Vorona E. Mechanisms in endocrinology: Medical consequences of doping with anabolic androgenic steroids: Effects on reproductive functions. Eur J Endocrinol. 2015;173(2):R4758.

180. Nieschlag E, Vorona E. Doping with anabolic androgenic steroids (AAS): Adverse effects on non-reproductive organs and functions. Rev Endocr Metab Disord. 2015;16(3):199-211.

181. Christou MA, Christou PA, Markozannes G, Tsatsoulis A, Mastorakos G, Tigas S. Effects of anabolic androgenic steroids on the reproductive system of athletes and recreational users: A systematic review and meta-analysis. Sport Med. 2017;47(9): 1869-83. 